\title{
Quantitative estimates of the volatility of ambient organic aerosol
}

\author{
C. D. Cappa ${ }^{1}$ and J. L. Jimenez ${ }^{2}$ \\ ${ }^{1}$ Department of Civil and Environmental Engineering, University of California, Davis, CA, USA \\ ${ }^{2}$ Cooperative Institute for Research in the Environmental Sciences (CIRES), and Department of Chemistry and Biochemistry, \\ University of Colorado, Boulder, CO, USA
}

Received: 31 December 2009 - Published in Atmos. Chem. Phys. Discuss.: 25 January 2010

Revised: 13 May 2010 - Accepted: 7 June 2010 - Published: 21 June 2010

\begin{abstract}
Measurements of the sensitivity of organic aerosol (OA, and its components) mass to changes in temperature were recently reported by Huffman et al. (2009) using a tandem thermodenuder-aerosol mass spectrometer (TD-AMS) system in Mexico City and the Los Angeles area. Here, we use these measurements to derive quantitative estimates of aerosol volatility within the framework of absorptive partitioning theory using a kinetic model of aerosol evaporation in the TD. OA volatility distributions (or "basis-sets") are determined using several assumptions as to the enthalpy of vaporization $\left(\Delta H_{\text {vap }}\right)$. We present two definitions of "non-volatile OA," one being a global and one a local definition. Based on these definitions, our analysis indicates that a substantial fraction of the organic aerosol is comprised of non-volatile components that will not evaporate under any atmospheric conditions; on the order of 50-80\% when the most realistic $\Delta H_{\text {vap }}$ assumptions are considered. The sensitivity of the total OA mass to dilution and ambient changes in temperature has been assessed for the various $\Delta H_{\text {vap }}$ assumptions. The temperature sensitivity is relatively independent of the particular $\Delta H_{\text {vap }}$ assumptions whereas dilution sensitivity is found to be greatest for the low $\left(\Delta H_{\mathrm{vap}}=50 \mathrm{~kJ} / \mathrm{mol}\right)$ and lowest for the high $\left(\Delta H_{\text {vap }}=150 \mathrm{~kJ} / \mathrm{mol}\right)$ assumptions. This difference arises from the high $\Delta H_{\text {vap }}$ assumptions yielding volatility distributions with a greater fraction of non-volatile material than the low $\Delta H_{\text {vap }}$ assumptions. If the observations are fit using a 1 or 2 -component model the sensitivity of the OA to dilution is unrealistically high. An empirical method introduced by Faulhaber et al. (2009) has also been used to independently estimate a volatility distribution for the ambient $\mathrm{OA}$ and is found to give results consistent with the high and variable $\Delta H_{\text {vap }}$ assumptions. Our results also show that the amount of semivolatile gas-
\end{abstract}

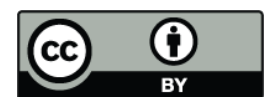

Correspondence to: C. D. Cappa (cdcappa@ucdavis.edu) phase organics in equilibrium with the OA could range from $\sim 20 \%$ to $400 \%$ of the OA mass, with smaller values generally corresponding to the higher $\Delta H_{\text {vap }}$ assumptions. The volatility of various OA components determined from factor analysis of AMS spectra has also been assessed. In general, it is found that the fraction of non-volatile material follows the pattern: biomass burning $\mathrm{OA}<$ hydrocarbonlike $\mathrm{OA}<$ semivolatile oxygenated $\mathrm{OA}<$ low-volatility oxygenated OA. Correspondingly, the sensitivity to dilution and the estimated amount of semivolatile gas-phase material for the OA factors follows the reverse order. Primary OA has a substantial semivolatile fraction, in agreement with previous results, while the non-volatile fraction appears to be dominated by oxygenated OA produced by atmospheric aging. The overall OA volatility is thus controlled by the relative contribution of each aerosol type to the total OA burden. Finally, the model/measurement comparison appears to require OA having an evaporation coefficient $\left(\gamma_{e}\right)$ substantially greater than $10^{-2}$; at this point it is not possible to place firmer constraints on $\gamma_{e}$ based on the observations.

\section{Introduction}

Atmospheric aerosol particles play an important role in the Earth's climate system through their ability to absorb and scatter solar radiation and influence the properties of clouds (IPCC, 2007) and have significant negative effects on human health (Nel, 2005; Pope and Dockery, 2006). Aerosols are comprised of a wide variety of materials, with organic species commonly making up about $50 \%$ of the submicron aerosol mass (Zhang et al., 2007). Despite the ubiquity of organic aerosol (OA), large uncertainties remain with respect to its formation, chemical evolution and removal mechanisms. Organic aerosol in the atmosphere derives from either primary emissions (termed POA) or from secondary formation following reactions of gas-phase compounds (termed SOA)

Published by Copernicus Publications on behalf of the European Geosciences Union. 
(Kanakidou et al., 2005; de Gouw and Jimenez, 2009). Atmospheric models of OA formation generally follow from absorptive partitioning theory (Pankow, 1994), using either a two-product (Odum et al., 1996) or volatility basis-set framework (Donahue et al., 2006; Robinson et al., 2007). Two different 2-dimensional basis sets have been recently proposed (Jimenez et al., 2009; Pankow and Barsanti, 2009). Unfortunately, the use of these "bottom-up" approaches in models, especially for the more complex ones, is limited by the lack of information on the volatility distributions of different types of OA, and perhaps for this reason it has typically led to either an under-estimate of ambient OA mass loadings (e.g. de Gouw et al., 2005; Heald et al., 2005; Volkamer et al., 2006; Kleinman et al., 2008) or model OA with physical properties, such as volatility, that are inconsistent with observations (Dzepina et al., 2009). Fully explicit chemical models are also under development (e.g. Johnson et al., 2006). These models are especially useful to benchmark smaller models, but they are limited by our current understanding of the detailed chemistry and are too computationally expensive for large-scale atmospheric models. The reader is referred to the recent review of Hallquist et al. (2009) for further details relating to SOA modeling.

Here, we use a detailed kinetic model of aerosol evaporation (Cappa, 2010) to quantitatively parameterize the volatility of ambient organic aerosol from measurements made in Mexico City during the MILAGRO campaign (Huffman et al., 2009a). Having specific knowledge of the volatility distribution of the compounds comprising ambient $\mathrm{OA}$ allows for more direct comparison with physical properties of model OA. Through this analysis, it is shown that a substantial fraction of the ambient OA in this region is extremely "nonvolatile," in that it would remain in the particle phase under any conditions in the Earth's atmosphere. Volatility distributions for OA using various assumptions for the enthalpy of vaporization of the OA fractions are derived. Implications of our results towards the amount of available gas-phase semivolatile material in the atmosphere and the sensitivity of OA to dilution are discussed.

\section{General approach}

Ambient OA volatility was quantified by determining distributions of ambient-temperature effective saturation concentrations $\left(C_{i}^{*}\right.$, in $\left.\mu \mathrm{g} / \mathrm{m}^{3}\right)$ that provide good agreement between model and measured mass thermograms from a thermodenuder-aerosol mass spectrometer system (TDAMS). Unless otherwise specified, all $C_{i}^{*}$ values refer to the values at $25^{\circ} \mathrm{C}$. The TD and the Aerodyne high-resolution AMS used in this work have been described by Huffman et al. (2009a) and DeCarlo et al. (2006) respectively. A TD consists of a heated tube followed by a denuder section where the gases are exposed to a charcoal adsorbent. A mass thermogram is a plot of the amount of OA mass remaining in the particle phase after passing the particles through a TD as a function of the thermodenuder temperature. Here, we focus on the mass thermograms for the campaign-average total OA and its components observed during MILAGRO (Huffman et al., 2009a).

$C_{i}^{*}$ is directly proportional to vapor pressure through the relationship

$C_{i}^{*}=\frac{M W_{i} 10^{6} p_{i, L} \zeta_{i}}{R T}$

where $M W_{i}$ is the molecular weight $(\mathrm{g} / \mathrm{mol}), R$ is the ideal gas constant $\left(8.314 \mathrm{~J} \mathrm{~mol}^{-1} \mathrm{~K}^{-1}\right), T$ is the temperature $(\mathrm{K})$, $\zeta_{i}$ is the activity coefficient in the OA phase and $p_{i, L}$ is the (sub-cooled liquid) saturation vapor pressure $(\mathrm{Pa})$ of compound $i$ (which may also represent a class of compounds). In specifying the $C_{i}^{*}$ distributions we have taken the approach of using a $\log _{10}$ volatility basis-set framework (Donahue et al., 2006). This framework keeps track of the amount of total organic material $\left(C_{i \text {,tot }}=C_{i, \text { gas }}+C_{i, \text { aer }}\right.$, gas + aerosol $)$ in each volatility bin, and the total $\mathrm{OA}$ concentration $\left(C_{\mathrm{OA}}\right)$ is calculated using the equation

$C_{\mathrm{OA}}=\sum_{i} C_{i, \text { tot }}\left(1+\frac{C_{i}^{*}}{C_{\mathrm{OA}}}\right)^{-1}$.

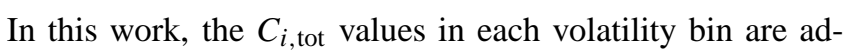
justed iteratively until the differences between the thermal denuder observations and simulations are minimized. An upper limit on $C^{*}$ of $1000 \mu \mathrm{g} / \mathrm{m}^{3}$ has been used here as higher volatility species are not constrained by the TD observations, and for most cases it is only possible to provide an approximate upper limit on the contribution of the $C^{*}=1000 \mu \mathrm{g} / \mathrm{m}^{3}$ bin. This is because the actual OA mass in the $C^{*}=1000 \mu \mathrm{g} / \mathrm{m}^{3}$ bin is, for these cases, only a small fraction of the total OA and thus does not strongly influence the overall calculated mass thermogram. Estimation of an upper-limit to the $C_{i, \text { tot }}$ for this bin is possible because if too large of values are used then the overall aerosol becomes too volatile in comparison with the observations.

For the lower limit $C^{*}$, we have taken the approach of trying to minimize the total number of bins required to obtain model/measurement agreement, while using a continuous set of bins. The variation of $C_{i, \text { tot }}$ values with $C^{*}$ is not known a priori. Here, we assume that the $C_{i, \text { tot }}$ vary exponentially with $C^{*}$, specifically that the distribution has the form $C_{i, \text { tot }}=a_{1}+a_{2} \exp \left[a_{3}\left(\log \left(C^{*}\right)-3\right)\right]$ (Table 1$)$. This form was chosen in part because it is generally consistent with observations of the volatility distributions determined for laboratory secondary OA (Presto and Donahue, 2006) and for OA from diesel and woodsmoke emissions (Robinson et al., 2007), but more importantly because it was found to provide generally good agreement between the model and observations. Note that this relationship should not be extrapolated to $C^{*}$ values above $\sim 10^{3} \mu \mathrm{g} / \mathrm{m}^{3}$ as the observations do not provide constraints on such high volatility species. We also 
Table 1. Parameters describing the volatility basis sets determined for the various $\Delta H_{\text {vap }}$ cases. Values are shown for the $\gamma_{e}=1$ and $\gamma_{e}=0.1$ cases, along with the values determined for the individual organic aerosol factors.

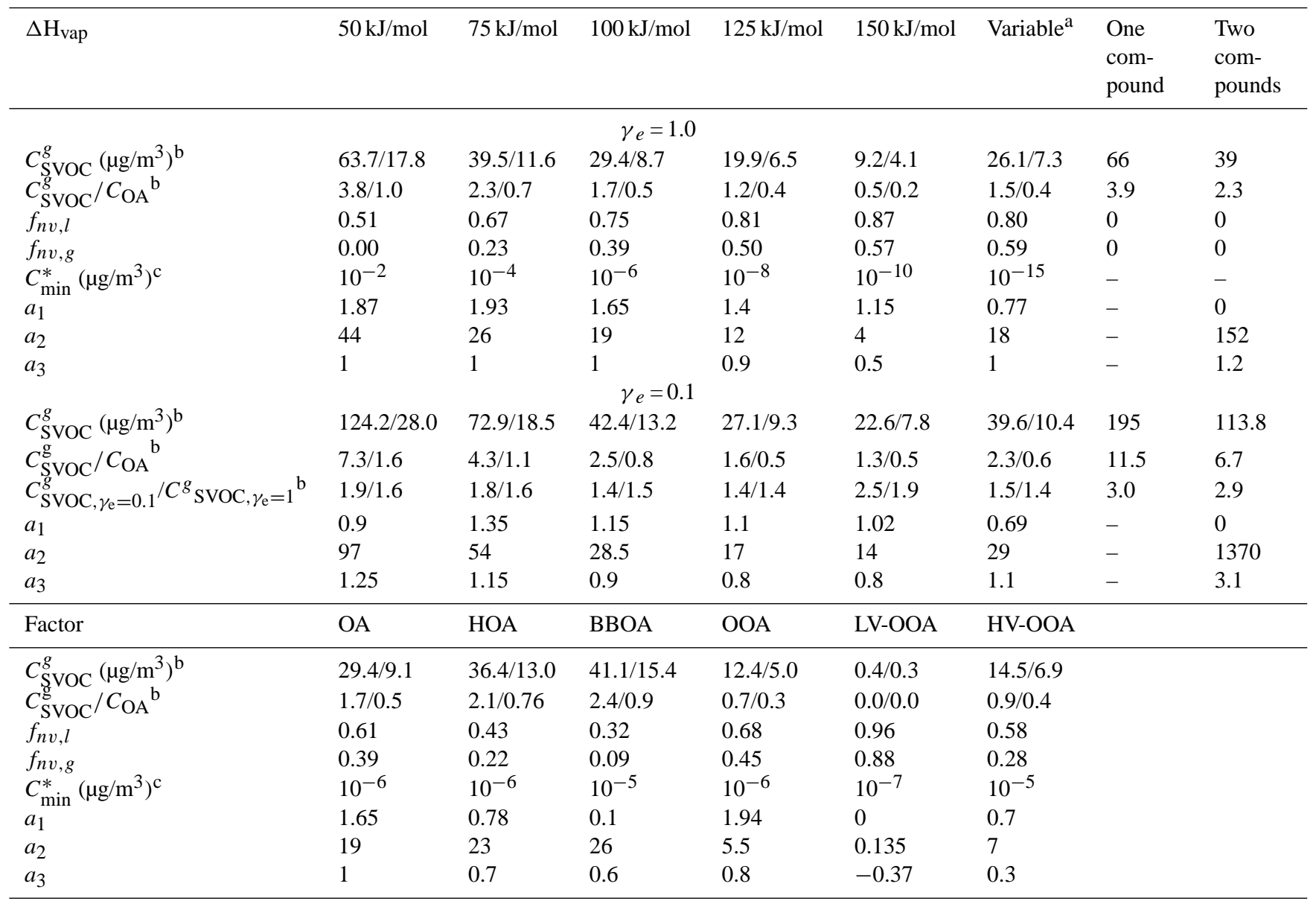

a $\Delta \mathrm{H}_{\mathrm{vap}}=131-11 \log \left(C^{*}\right)$ with maximum $\Delta \mathrm{H}_{\mathrm{vap}}=200 \mathrm{~kJ} / \mathrm{mol}$.

b The first value reported includes all compounds with $C^{*}<=1000 \mathrm{mg} / \mathrm{m}^{3}$ and the second all compounds with $C^{*}<=100 \mu \mathrm{g} / \mathrm{m}^{3}$.

${ }^{\mathrm{c}} C_{\min }^{*}$ is the lowest $C^{*}$ bin required to match the observations.

considered a linear relationship between $C_{i, \text { tot }}$ and $C^{*}$; this

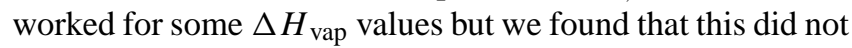
provide as robust results as the exponential relationship for all cases considered. It is likely that other forms (e.g. a power law, square dependence, etc.) of the relationship would allow for determination of volatility basis-sets that also would provide good model/measurement agreement.

In addition to specifying the $C_{\text {tot }}$ distribution, it is necessary to specify the temperature dependence of the $C_{i}^{*}$ for each basis set bin. We have assumed that the temperature dependence of $C^{*}$ can be specified assuming vapor pressures vary according to the Clausius-Clapeyron equation such that

$C^{*}(T)=C^{*}\left(T_{\text {ref }}\right)\left(\frac{T_{\text {ref }}}{T}\right) \exp \left[-\frac{\Delta H_{\text {vap }}}{R}\left(\frac{1}{T}-\frac{1}{T_{\text {ref }}}\right)\right]$
Like the $C_{\text {tot }}$ distribution, the variation of $\Delta H_{\text {vap }}$ with $C^{*}$ is not known a priori. We consider here a number of different assumptions, either using a single $C^{*}$ independent $\Delta H_{\text {vap }}$ or allowing $\Delta H_{\text {vap }}$ to vary with $C^{*}$. For the variable $\Delta H_{\text {vap }}$ assumption, we have used a modified form of the semi-empirical relationship established by Epstein $e t$ al. (2009):

$\Delta H_{\mathrm{vap}}=131-11 \log \left(C^{*}\right) ; \Delta H_{\mathrm{vap}}<200 \mathrm{~kJ} / \mathrm{mol}$.

Our modification is to specify an upper-limit of $200 \mathrm{~kJ} / \mathrm{mol}$ on the $\Delta H_{\text {vap }}$ values. This limit affects only those compounds with ambient temperature $C^{*}$ values $\leq 10^{-7} \mu \mathrm{g} / \mathrm{m}^{3}$. Without this limit, we find that $\Delta \mathrm{H}_{\mathrm{vap}}$ values become unrealistically large for very low volatility species, and we are unable to determine a basis set that gives reasonable model/measurement agreement. Note that this is a somewhat 
arbitrary limit, but is consistent with the largest $\Delta H_{\text {vap val- }}$ ues determined for individual dicarboxylic acids (Cappa et al., 2007) and, more generally, with the largest $\Delta H_{\text {vap values }}$ reported for a wide variety of organic compounds (Chickos and Acree, 2003). For the fixed $\Delta H_{\text {vap }}$ assumptions, we have considered $\Delta H_{\text {vap }}=50,75,100,125$ and $150 \mathrm{~kJ} / \mathrm{mol}$.

The model used is a time-dependent, multi-component evaporation model wherein the evolution of both the particle and gas-phase as they pass through a thermodenuder are simulated (Cappa, 2010). The model accounts for the effects of heating of the particles and for denuding of the gas-phase. It is assumed that the particle/gas system is initially in equilibrium at ambient temperature $\left(25^{\circ} \mathrm{C}\right)$ and that the aerosol is describable according to partitioning theory (Pankow, 1994; Odum et al., 1996) and that the particles therefore exhibit liquid-like behavior (i.e. are well-mixed). Liquid-like behavior is generally expected given the numerous compounds that likely comprise the OA (Marcolli et al., 2004; Cappa et al., 2008) and is the basis of all models that implement secondary OA formation. The initial equilibrium state depends on the specified $C_{\text {tot }}$ distribution and the total $C_{\mathrm{OA}}$. We use here $C_{\mathrm{OA}}=17 \mu \mathrm{g} / \mathrm{m}^{3}$ to be consistent with the campaign average $C_{\mathrm{OA}}$ observed during MILAGRO (Aiken et al., 2009). The results are somewhat sensitive to the choice of the initial particle diameter $\left(d_{p}\right)$, the gas-phase diffusion coefficient $\left(D_{i}\right)$ and the assumed residence time in the thermodenuder $\left(t_{\text {res }}\right)$, as discussed in Cappa (2010). To be consistent with the measurements we have used $t_{\text {res }}=16 \mathrm{~s}$ at ambient temperature, which decreases as the temperature increases due to the expansion of the gas (Huffman et al., 2009a). We have used values of $d_{p}=250 \mathrm{~nm}$ and of $D_{i}=3.5 \times 10^{-6} \mathrm{~m}^{2} / \mathrm{s}$. For reference, this choice of $D_{i}$ corresponds approximately to the diffusivity of a straight-chain $C_{16}$ hydrocarbon (Hilal et al., 2003). Smaller compounds are likely to have somewhat higher $D_{i}$ values, but as shown in Cappa (2010) the choice of a larger value for $D_{i}$ will lead to a shift of the mass thermogram to lower temperatures by only a few degrees. Similarly, choosing to use a larger (smaller) $d_{p}$ will lead to a shift of the calculated mass thermogram to higher (lower) temperatures by only a few degrees. As will be seen below, the uncertainty in these values is much less important for the final result compared to the lack of specific knowledge of the $\Delta H_{\text {vap }}$ distribution.

The model also requires as input a value for the evaporation coefficient, $\gamma_{e}$, (i.e. mass accommodation coefficient). Estimates of the evaporation coefficient for organic aerosol are currently uncertain. It has been suggested that it is generally appropriate to assume $\gamma_{e}=1$ (Pound, 1972; Cammenga, 1980; Davis et al., 1980; Kulmala and Wagner, 2001). However, some recent measurements for individual dicarboxylic acids suggest that lower values $\left(\gamma_{e} \sim 0.1\right)$ may be possible (Saleh et al., 2009). Also, dilution measurements using laboratory-generated secondary and primary OA have been interpreted as indicating even lower values $\left(0.001<\gamma_{e}<0.01\right)$ (Grieshop et al., 2007; Grieshop et al., 2009b). Given the current uncertainties in $\gamma_{e}$ for organic aerosol, we have considered the model results using $\gamma_{e}=1,0.1$ and 0.01 . Our general discussion will be based on the assumption that $\gamma_{e}=1$, and the lower values will be discussed as specific cases.

The observations against which the model results are compared are from the 2006 MILAGRO campaign in Mexico City (Molina et al., 2010). The volatility of OA was determined by passing the ambient aerosol through a thermodenuder (Huffman et al., 2008) at a series of temperatures while monitoring the submicron aerosol (and specifically the $\mathrm{OA})$ concentration and composition using an Aerodyne highresolution aerosol mass spectrometer (DeCarlo et al., 2006) as reported by Huffman et al. (2009a). The measurements were carried out at the "T0" Supersite located inside Mexico city about $9 \mathrm{~km} \mathrm{NNW}$ of the city center. A complete mass thermogram was obtained every 160 minutes and measurements were made semi-continuously for 2 weeks. The analysis here is focused on the average total OA thermograms. However, it was observed that there were substantial differences in the thermograms of different OA factors, as deduced from positive matrix factorization (PMF) of the mass spectral time series (Huffman et al., 2009a; Ulbrich et al., 2009). The various OA "types" arising from this analysis have different spectral signatures, correlations with external tracers, time series, diurnal cycles, and size distributions, and are therefore assumed to derive from different sources and/or have different formation mechanisms. Factor analysis of the MILAGRO dataset identified several OA types, which are similar to those identified elsewhere (Jimenez et al., 2009), namely oxygenated OA (OOA, a surrogate of secondary OA), hydrocarbon-like OA (HOA, a surrogate of anthropogenic combustion primary OA) and biomass burning OA (BBOA), which was dominated by smoke from fires near Mexico City (Aiken et al., 2010). The OOA component appeared to be less volatile, and the HOA and BBOA factors slightly more volatile than the average OA. These differences will be briefly addressed. Although not explicitly modeled here, Huffman et al. (2009a) also presented results for Riverside, CA, a polluted location in the Los Angeles Basin where OA was dominated by SOA (Docherty et al., 2008). The thermograms for Riverside are similar to those from Mexico City (Huffman et al., 2009a), and thus the general conclusions from this work are expected to be broadly applicable to similar locations dominated by anthropogenic pollution.

\section{Results and discussion}

\subsection{Volatility distributions from model-measurement comparison}

It is possible to determine a volatility basis-set that provides for good agreement between the model and observed mass thermograms of total OA for each of the $\Delta H_{\text {vap }}$ distributions considered, for both the fixed and variable $\Delta H_{\text {vap }}$ 


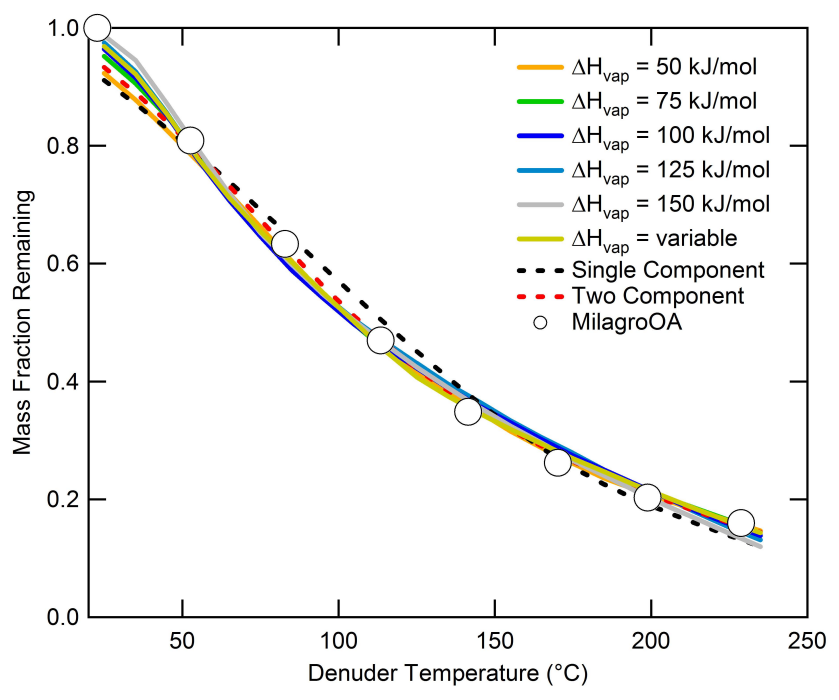

Fig. 1. Calculated (lines) and observed (circles) mass thermograms for the campaign average organic aerosol from Mexico City. Results are shown for each of the different $\Delta H_{\text {vap }}$ cases considered. The dashed lines in are the model results assuming the OA is comprised of only one (black) or two (red) components.

assumptions (Figs. 1 and 2). This indicates that a unique volatility distribution for ambient aerosol cannot be established without better knowledge of the appropriate $\Delta H_{\text {vap }}$ distribution to use.

As mentioned above, if the semi-empirical relationship determined by Epstein et al. (2009) is used without modification it is not possible to determine a volatility distribution that is consistent with the observations. This is because as $\Delta H_{\text {vap }}$ increases the sensitivity of $C^{*}$ to temperature changes increases; the sharp increase in $\Delta H_{\text {vap }}$ essentially offsets the decrease in $C^{*}$ such that even extremely low $C^{*}$ material does not persist to high enough temperatures (see Fig. S1). However, when an upper-limit was placed on $\Delta H_{\text {vap }}$, it was possible to match the observations. This is because by placing an upper limit on $\Delta H_{\text {vap }}$ the increase in $C^{*}$ with temperature for the lowest volatility components is not as strong as when no limit is used. For the variable $\Delta H_{\text {vap }}$ assumption extremely low volatility material $\left(C^{*}=10^{-15} \mu \mathrm{g} / \mathrm{m}^{3}\right)$ was required to match the observations. This result derives from the strong temperature dependence of the low $C^{*}$ components such that the differences in volatility between the $C^{*}$ bins (initially a factor of 10 at $298.15 \mathrm{~K}$ ) are reduced as temperature increases. If the upper-limit on $\Delta H_{\text {vap }}$ is adjusted to be higher (lower), it was found that the minimum $C^{*}$ bin required to match the observations is lower (higher).

It is also possible to determine volatility distributions that provide good model/measurement agreement using the $C^{*}$ independent $\Delta H_{\text {vap }}$ values (Figs. 1 and 2). An inverse relationship between the needed number of basis-set bins (or, equivalently, the minimum $C^{*}$ ) and the assumed $\Delta H_{\text {vap }}$ was found to exist, with higher $\Delta H_{\text {vap }}$ values requiring lower $C^{*}$ values, for the reason described above (Table 1 ). We find it is also possible to match the observations assuming the total OA was composed of as few as one or two compounds, if the $\Delta H_{\text {vap }}$ and $C^{*}$ values are judiciously selected (Figs. 1 and 2). This is analogous to the one or two-product models originally used for secondary OA modeling (Odum et al., 1996). However, this requires physically unrealistically low values for $\Delta H_{\text {vap }}(19 \mathrm{~kJ} / \mathrm{mol}$ or 28 and $22 \mathrm{~kJ} / \mathrm{mol}$ for one or two components, respectively) and relatively large $C^{*}$ values $\left(C^{*}=36 \mu \mathrm{g} / \mathrm{m}^{3}\right.$ for the one component or 45 and $10 \mu \mathrm{g} / \mathrm{m}^{3}$ for two component case). Similarly high values of $C^{*}$ have been reported when fitting two-product models to chamber yield data vs. $C_{\mathrm{OA}}$ at room temperature (e.g. Griffin et al., 1999). Similarly low $\Delta H_{\text {vap }}$ values have often been previously used to describe the overall sensitivity of OA to changes in temperature (Donahue et al., 2005; Offenberg et al., 2006; Stanier et al., 2007). However, as was pointed out by Donahue et al. (2006), the use of such low values is only valid as a simplification when attempting to represent the aerosol as a whole as one or very few lumped components (Donahue et al., 2006); when individual compounds (or a wide range of volatility bins) are used (such as is the case here) the use of larger $\Delta H_{\text {vap }}$ values, consistent with the properties of individual compounds, is more appropriate. As such, the variable $\Delta H_{\text {vap }}$ or $\Delta H_{\text {vap }} \geq 100 \mathrm{~kJ} / \mathrm{mol}$ might be considered the most realistic of the assumptions used here.

In each of the above cases we have assumed that $\Delta H_{\text {vap }}$ is temperature independent. However, $\Delta H_{\text {vap }}$ values actually decrease somewhat with temperature. We have therefore also considered how use of a temperature dependent $\Delta H_{\text {vap }}$ in our model influences our results. We have assumed $\Delta H_{\text {vap }}(T)=\Delta H_{\text {vap }}\left(T_{\text {ref }}\right)-\Delta \mathrm{C}_{p}\left(T-T_{\text {ref }}\right)$, where $\Delta \mathrm{C}_{p}$ is the difference in heat capacities between the condensed and gaseous states $\left(\mathrm{J} \mathrm{mol}^{-1} \mathrm{~K}^{-1}\right)$ (MacLeod et al., 2007) and $T_{\text {ref }}=298.15 \mathrm{~K}$. Accordingly, $C^{*}(T)$ values are determined through an iterative process. In general, we find that the influence of allowing for a T-dependent $\Delta H_{\text {vap }}$ is greatest for the low $\Delta H_{\mathrm{vap}}$ assumptions and smallest for the high and variable $\Delta H_{\text {vap }}$ assumptions. This is as expected given that the TD model results generally show a greater sensitivity to changes in $\Delta H_{\text {vap }}$ at low $\Delta H_{\text {vap }}$ than at high $\Delta H_{\text {vap }}$ for individual components (Cappa, 2010). The actual magnitude of the influence depends explicitly on the assumed $\Delta \mathrm{C}_{p}$ value. If we use $\Delta \mathrm{C}_{p}=0.12 \mathrm{~kJ} \mathrm{~mol}^{-1} \mathrm{~K}^{-1}$, which is the value for malonic acid from Epstein et al. (2009), then for the most realistic high and variable $\Delta H_{\text {vap }}$ assumptions the use of a $T$-dependent $\Delta H_{\text {vap }}$ has only a very small influence on the derived volatility distributions. For the lowest $\Delta H_{\text {vap }}$ assumptions, use of the $T$-dependent $\Delta H_{\text {vap }}$ with $\Delta \mathrm{C}_{p}=0.12 \mathrm{~kJ} \mathrm{~mol}^{-1} \mathrm{~K}^{-1}$ leads to an aerosol that is somewhat more volatile than for the $\mathrm{T}$-independent case. If we use a much larger value for $\Delta \mathrm{C}_{p}\left(0.5 \mathrm{~kJ} \mathrm{~mol}^{-1} \mathrm{~K}^{-1}\right)$, the resulting $150 \mathrm{~kJ} / \mathrm{mol}$ and variable $\Delta H_{\text {vap }}$ volatility distributions do change qualitatively to some extent (the necessary minimum 

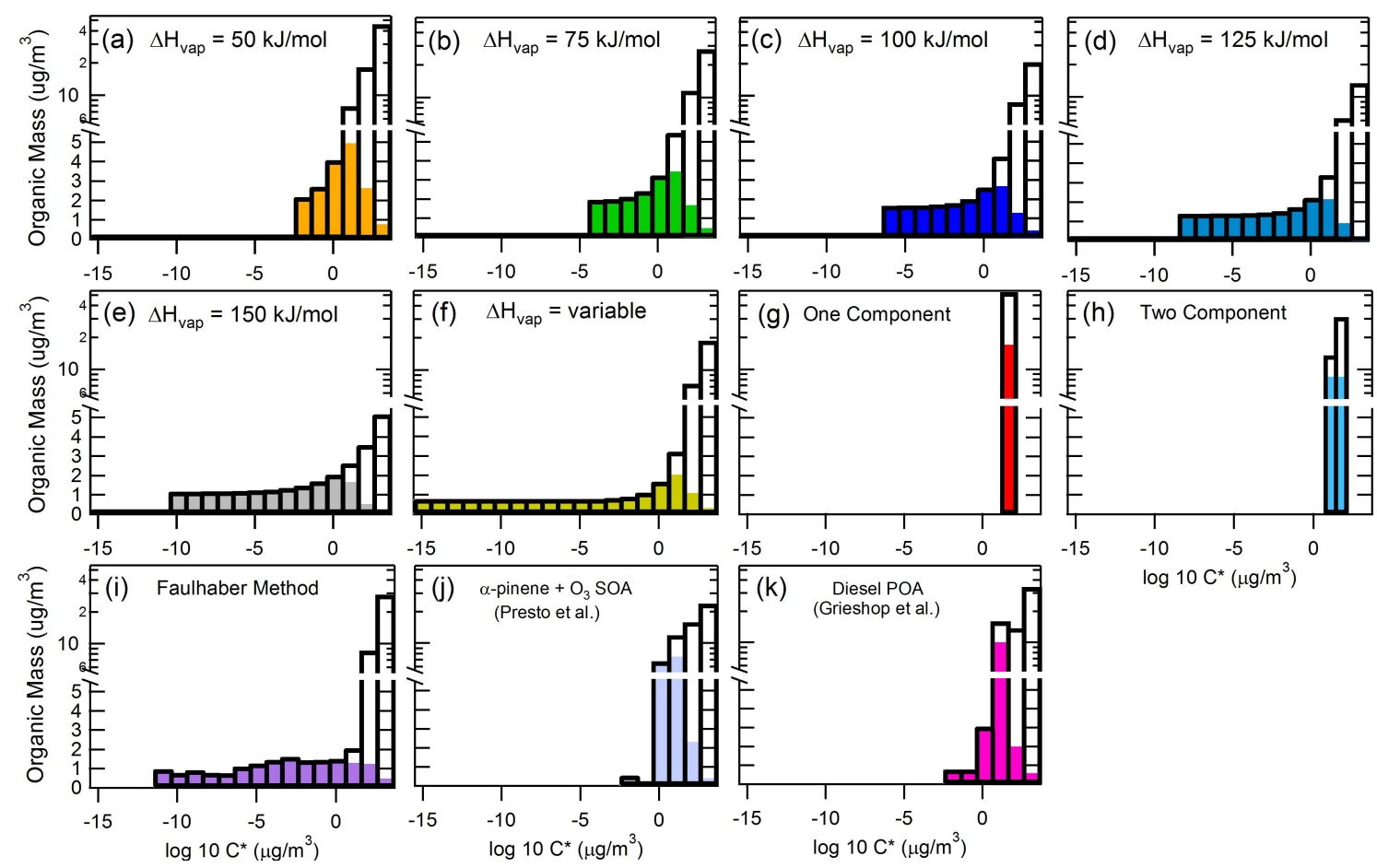

$\log 10 C^{*}\left(\mu \mathrm{g} / \mathrm{m}^{3}\right)$

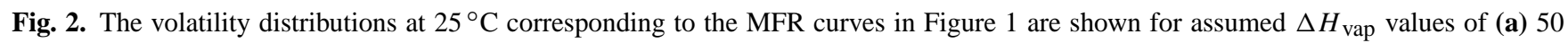
$\mathrm{kJ} / \mathrm{mol}$, (b) $75 \mathrm{~kJ} / \mathrm{mol}$, (c) $100 \mathrm{~kJ} / \mathrm{mol}$, (d) $125 \mathrm{~kJ} / \mathrm{mol}$, (e) $150 \mathrm{~kJ} / \mathrm{mol}$ and (f) the variable $\Delta \mathrm{H}_{\mathrm{vap}}$ assumptions. Distributions are also shown for the (g) 1-component and (h) 2-component cases and (i) for that determined using the empirical relationship from Faulhaber et al. (2009). For comparison, volatility distributions for (j) SOA from the $\alpha$-pinene $+\mathrm{O}_{3}$ reaction (Presto et al., 2006) and (k) diesel emissions POA (Grieshop et al., 2009). Note that there is a break and change from linear to a log scale for the y-axis. In the distributions, the black boxes correspond to the total organic mass (gas + particle phase) and the colored boxes correspond to the particle phase only.

$C^{*}$ increases), but importantly the quantitative aspects (such as sensitivity to dilution and the non-volatile fractions, discussed below) are changed from the T-independent cases by less than $10 \%$.

Alternatively, Faulhaber et al. (2009) introduced an empirical method for inferring volatility distributions from measured mass thermograms. Specifically, they related the $T_{50}$ (the temperature at which $50 \%$ of the mass remains for a given compound or component) to the compound vapor pressure. They calibrated this method using a number of relatively low volatility compounds with high $\Delta H_{\text {vap }}$ values ( $C^{*}$ ranging from $\sim 0.1-10 \mu \mathrm{g} / \mathrm{m}^{3}$ and $\Delta H_{\text {vap }}$ from $\sim 120-$ $150 \mathrm{~kJ} / \mathrm{mol}$ ). We have used their calibration curve to deduce a volatility distribution for the MILAGRO OA. The volatility distribution determined using the Faulhaber et al. (2009) relationship was found to be most similar to that derived under the $\Delta H_{\text {vap }}=150 \mathrm{~kJ} / \mathrm{mol}$ and the variable $\Delta H_{\text {vap }}$ assumptions, which is to be expected given the nature of the compounds used in their calibration (see Figure 2).

These volatility distributions, derived from the ambient observations, can be compared with volatility distributions determined for laboratory SOA (e.g. $\alpha$-pinene $+\mathrm{O}_{3}$ (Stanier et al., 2007)) and POA (e.g. diesel and wood smoke aerosol, Grieshop et al., 2009b) (Fig. 2). The lowest $C^{*}$ bin con- sidered in these previous studies was $10^{-2} \mu \mathrm{g} / \mathrm{m}^{3}$ and furthermore there was very little material in the $C^{*}=10^{-1}$ and $10^{-2} \mu \mathrm{g} / \mathrm{m}^{3}$ bins. As such, the volatility of the laboratory SOA and POA appears to be significantly greater than that of the derived ambient distributions, even compared to the distribution derived using the $\Delta H_{\text {vap }}=50 \mathrm{~kJ} / \mathrm{mol}$ assumption. This result is consistent with the mass fraction remaining for the laboratory aerosol going to zero at much lower temperatures than in the ambient observations (Grieshop et al., 2009b; Huffman et al., 2009b).

To summarize:

- Ambient temperature volatility distributions for OA have been derived via model/measurement comparison for TD measurements made as part of MILAGRO.

- The specific nature of the derived volatility distributions depends explicitly on the assumed values of $\Delta H_{\text {vap }}$ used.

- The use of higher ( $\geq 100 \mathrm{~kJ} / \mathrm{mol})$, more realistic, $\Delta H_{\mathrm{vap}}$ values or $C^{*}$-dependent $\Delta H_{\text {vap }}$ values generally leads to volatility distributions with lower volatility material compared to when lower $(<100 \mathrm{~kJ} / \mathrm{mol}) \Delta H_{\text {vap }}$ values are used. 


\subsection{Dilution and the atmospheric non-volatile fraction}

Here, we introduce two definitions of the "atmospheric nonvolatile" OA material and the corresponding non-volatile fraction. The first can be considered as a local definition, wherein compounds having $C^{*}<C_{\mathrm{OA}} / 20$ are considered nonvolatile. With this definition, the $C^{*}$ of non-volatile material depends explicitly on the concurrent aerosol mass concentration and temperature, i.e. for our case, a "locally nonvolatile" species will not evaporate appreciably under the average conditions in downtown Mexico City. The second definition can be considered as a global non-volatile fraction, and refers to compounds with $C^{*}$ values such that they will always be nearly entirely in the particle phase under almost all conditions found on the Earth's atmosphere. We determine this global non-volatile $C^{*}$ by identifying the bins that remain $>95 \%$ in the particle phase when the Mexico City OA is diluted to $0.1 \mu \mathrm{g} / \mathrm{m}^{3}$ at a temperature of $40^{\circ} \mathrm{C}$.

Considering each of the $\Delta H_{\text {vap }}$ assumptions individually, we find that, in general, compounds with $C^{*} \leq 10^{-3} \mu \mathrm{g} / \mathrm{m}^{3}$ can be considered globally non-volatile (see Figure S2). Note that these definitions are less arbitrary than the OA mass fraction remaining at some pre-specified temperature in a thermodenuder or a volatility tandem differential mobility analyzer (Kalberer et al., 2004) as they are independent of the specific experimental details such as residence time or particle size. However, to facilitate interpretations of TD measurements we have calculated the temperature at which only $50 \%$ of the material with $C^{*}=10^{-3} \mu \mathrm{g} / \mathrm{m}^{3}$ (termed $T_{50, n v}$ ) remains for the different $\Delta H_{\text {vap }}$ assumptions for the residence time of the TD used in the Huffman et al. (2009a) study. Above this temperature, it can reasonably be assumed that the remaining material is globally non-volatile. The $T_{50, n v}$ values range from $\sim 225^{\circ} \mathrm{C}\left(\Delta H_{\text {vap }}=75 \mathrm{~kJ} / \mathrm{mol}\right)$ to $\sim 100^{\circ} \mathrm{C}$ $\left(\Delta H_{\text {vap }}=150 \mathrm{~kJ} / \mathrm{mol}\right)$, with the variable $\Delta H_{\text {vap }}$ assumption (for which $\Delta H_{\text {vap }}=164 \mathrm{~kJ} / \mathrm{mol}$ at $C^{*}=10^{-3} \mu \mathrm{g} / \mathrm{m}^{3}$ ) giving the lowest $T_{50, n v}$ value, $\sim 92^{\circ} \mathrm{C}$ (see Figure S3). Thus, we see that a generally applicable value for $T_{50, n v}$ cannot be determined in the absence of more specific information as to the appropriate $\Delta H_{\text {vap }}$ values to use to describe OA volatility. We therefore conservatively suggest that for the TD used by Huffman et al. (2009a) and other similarly designed TD's, at temperatures greater than $150{ }^{\circ} \mathrm{C}$ the $\mathrm{OA}$ remaining can very likely be considered as globally non-volatile and that at temperatures greater than $100^{\circ} \mathrm{C}$ the $\mathrm{OA}$ remaining can probably be considered as globally non-volatile.

Depending on the assumed $\Delta H_{\text {vap }}$, the locally nonvolatile fraction, $f_{n v, l}$, of OA during MILAGRO varies from $26 \%$ to $71 \%$ (Table 1 ). The corresponding globally nonvolatile fraction, $f_{n v, g}$, varies from 0 to $59 \%$ (Table 1). In general, both $f_{n v, l}$ and $f_{n v, g}$ increase with the assumed $\Delta H_{\text {vap }}$ and are largest for the variable $\Delta H_{\text {vap }}$ assumption. Alternatively, using the volatility distribution deduced using Faulhaber et al. (2009) relationship discussed above, $f_{n v, g}=56 \%$. Such a large fraction of non-volatile mate- rial is consistent with an important role for condensed-phase chemistry (Kalberer et al., 2004) or heterogeneous reactions (Smith et al., 2009), and is a result of oxygenated OA being a substantial fraction of the overall Mexico City OA. Gas-phase mechanisms have difficulty producing very low $C^{*}$ compounds because compounds with $C^{*} \leq C_{\mathrm{OA}}$ are more than $50 \%$ partitioned to the particle phase and functionalization through typical gas-phase $\mathrm{OH}+$ hydrocarbon reactions are not likely to lead to a decrease in $C^{*}$ by more than ca. a factor of 1000. For example, the addition of a single ketone function group to a straight-chain saturated hydrocarbon decreases the vapor pressure by approximately a factor of 10 , the addition of an alcohol group by a factor of 100 and the addition of a carboxylic acid group by a factor of 1000 (c.f. Fig. 1b in Goldstein and Galbally, 2007). These composition-volatility relationships are only approximate and do not fully account for multi-functional compounds, which can show significant deviations. Nonetheless, starting with compounds with $C^{*}=17 \mu \mathrm{g} / \mathrm{m}^{3}$ (the MILAGRO campaign average), gas-phase reactions will likely only lead to production of significant concentrations of material with $C^{*} \geq \sim 10^{-2} \mu \mathrm{g} / \mathrm{m}^{3}$. The observed Mexico City OA volatility was lowest towards the end of the day (Huffman et al., 2009a), following the period when photochemical activity and secondary organic aerosol formation was highest. This suggests that the reactions that form the low volatility material are relatively fast, occurring on a time-scale of a few hours.

We note that it is possible that some of the species present in the aerosol at high temperatures may be formed in the thermodenuder itself due to heating, as previously suggested (Denkenberger et al., 2007). Particle-phase chemical reactions that are enhanced at higher temperatures could either lead to production of lower volatility material (such as from accretion reactions) or to lower volatility material (from decomposition reactions). However, this type of chemistry is most likely at the higher temperatures in the TD, and the previous results only suggested chemical reactions occurring at $150^{\circ} \mathrm{C}$ and above. Therefore, although the detailed volatility distribution of the lower volatility bins is the most uncertain, the fact that a substantial fraction of the ambient OA is effectively non-volatile is not given our estimate of the $T_{50, n v}$ above. Further research using fully-speciated chemical analysis techniques may be useful to further understand the effect of TD heating on OA chemistry.

The sensitivity of the total OA burden to factors other than temperature changes, such as dilution, will depend explicitly on the non-volatile fraction. A greater amount of nonvolatile material will lead to a lower sensitivity of $C_{\mathrm{OA}}$ to dilution. SOA formed from two-product models undergoes very rapid evaporation upon dilution, which is probably unrealistic (Dzepina et al., 2009). Similarly high evaporation would be predicted with the one or two product fits to the thermal denuder data, since the values of $C^{*}$ and $\Delta H_{\text {vap }}$ are similar to those in typical SOA 2-product models. As the 
evolution of $C_{\mathrm{OA}}$ upon dilution is sensitive to the organic gas and particle-phase concentrations in the dilution air, we have assessed these effects for the various $\Delta H_{\text {vap }}$ assumptions by establishing an upper-limit to the sensitivity of the $C_{\mathrm{OA}}$ to a given dilution. An upper-limit is obtained by assuming that the dilution air is perfectly clean (i.e. $C_{\mathrm{OA}}=0$ and $C_{\text {gas }}=0$ ). Dilution is therefore implemented simply by dividing the initial $C_{\text {tot }}$ by the dilution factor and calculating the new equilibrium condition (i.e. a dilution factor of 2 corresponds to a $50 \%$ decrease in the total organic concentration.) The influence of evaporation on the OA mass for a given dilution factor is characterized by calculating the percent difference from the mass loss that results from dilution before re-equilibration,

$E_{\mathrm{loss}}=100 \%\left[1-\frac{C_{\mathrm{OA}}(\mathrm{DF})}{C_{\mathrm{OA}}(0) / \mathrm{DF}}\right]$

where $\mathrm{DF}$ is the dilution factor, $C_{\mathrm{OA}}(\mathrm{DF})$ is the reequilibrated $C_{\mathrm{OA}}$ after dilution, $C_{\mathrm{OA}}(0)$ is the $\mathrm{OA}$ mass prior to dilution, and $E_{\text {loss }}$ is the relative mass loss due to evaporation of semivolatile components. A value of $E_{\text {loss }}=50 \%$ corresponds to a factor of 2 decrease in the OA mass concentration from evaporation only.

As expected based on the calculated $f_{n v}$ values, the variable $\Delta H_{\text {vap }}$ assumption shows the weakest response to dilution (i.e. has the smallest $E_{\text {loss }}$ values), and for the fixed $\Delta H_{\text {vap }}$ assumptions the response to dilution increases with decreasing assumed $\Delta H_{\text {vap }}$ (Fig. 3a) because more material is present in bins of higher $C^{*}$. The response of the one and two component cases to dilution is very large, with all of the OA evaporating for dilution factors $<2$. This is because for these cases, as dilution proceeds, $C_{\text {tot }}$ drops below the minimum $C^{*}$ and all of the OA evaporates. Using the constant $\Delta H_{\text {vap }}=100 \mathrm{~kJ} / \mathrm{mol}$ assumption as a reference, there is an approximately constant difference in the $E_{\text {loss }}$ values between different $\Delta H_{\text {vap }}$ assumptions (Fig. 3b). For the cases with higher $\Delta H_{\text {vap }}$ values (including the variable assumption) $E_{\text {loss }}$ is smaller by $20-30 \%$, while for the cases with lower $\Delta H_{\text {vap }}$ values $E_{\text {loss }}$ is greater by $30 \%(75 \mathrm{~kJ} / \mathrm{mol})$ to $100 \%(50 \mathrm{~kJ} / \mathrm{mol})$. For the two-component case, which is analogous to two-product OA formation models (e.g. Odum et al., 1996), the aerosol is predicted to completely evaporate when the dilution factor is $\geq 1.6$; the two-component model $\mathrm{OA}$ is extremely sensitive to dilution.

We compare these results, determined using volatility distributions constrained by the measurements, to that obtained using the volatility distributions determined by Dzepina et al. (2009), where they used a photochemical box-model to simulate the evolution of the gas and particle phase organics on a specific day during the MCMA-2003 campaign, also in downtown Mexico City (Dzepina et al., 2009). We assume here isothermal dilution and thus specification of $\Delta H_{\text {vap }}$ values is not necessary for this comparison. Here, we use the $C_{\text {tot }}$ distributions that were determined by Dzepina et

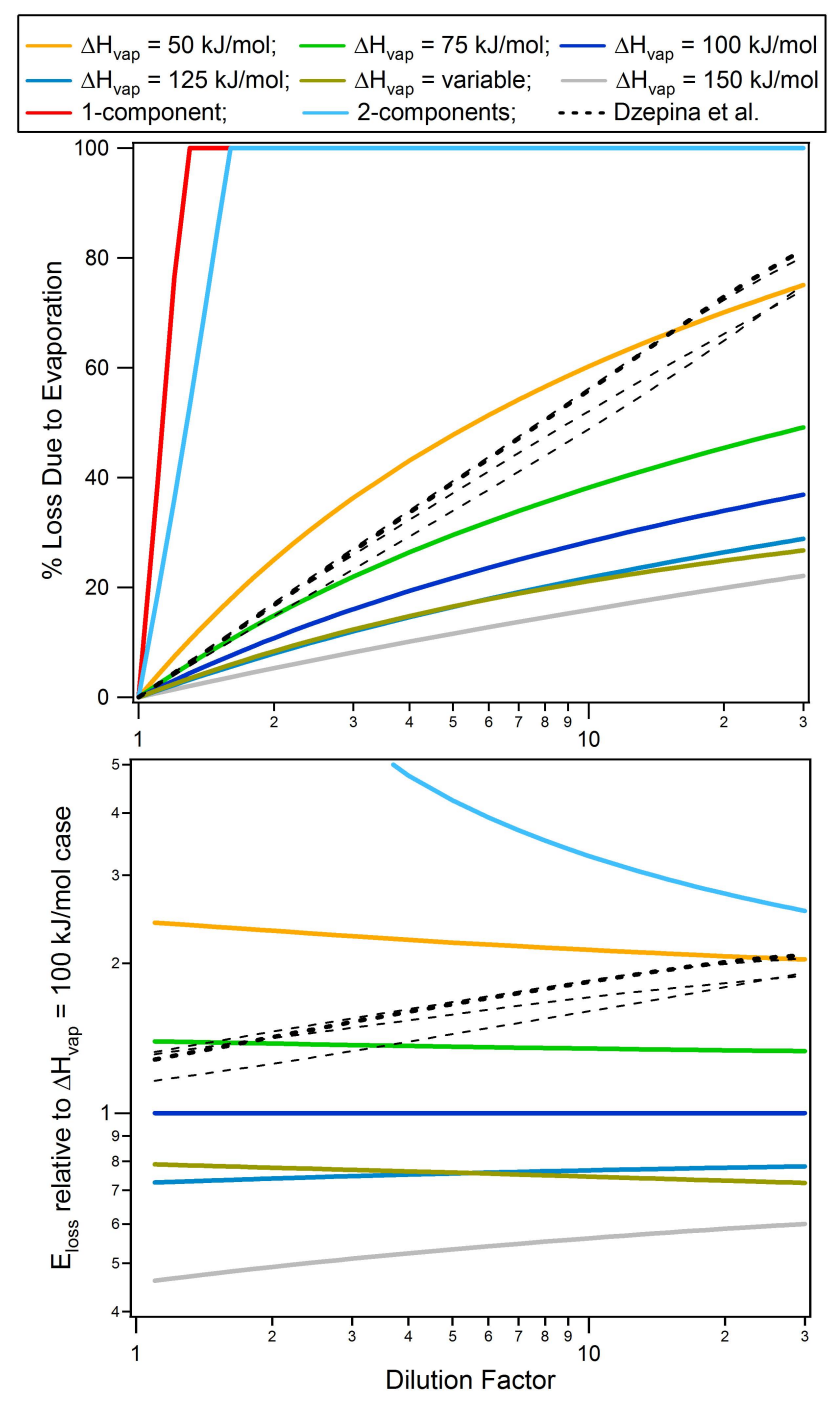

Fig. 3. (top) The $E_{\text {loss }}$, or the additional mass loss due to evaporation after dilution, is shown as a function of the dilution factor for the various $\Delta H_{\text {vap }}$ cases (see legend; colors correspond to Fig. 2). The dashed lines correspond to the results when the Dzepina et al. (2009) volatility distributions are used; the thick line is for the 02:00 p.m. case and the thin lines are for other times. (bottom) The various $E_{\text {loss }}$ are shown relative to that calculated for the $\Delta H_{\mathrm{vap}}=100 \mathrm{~kJ} / \mathrm{mol}$ case.

al. (2009) for 06:00 a.m., 09:00 a.m., 12:00 pm and 02:00 pm (c.f. their Fig. 8). The minimum $C^{*}$ considered in the Dzepina et al. (2009) study was $10^{-2} \mu \mathrm{g} / \mathrm{m}^{3}$ and the $C_{\mathrm{OA}}$ at each time are given in Table 2 . The sensitivity of $C_{\mathrm{OA}}$ to dilution using the distributions determined by Dzepina et al. falls in between that determined here for the constant $\Delta H_{\text {vap }}=50 \mathrm{~kJ} / \mathrm{mol}$ and $\Delta H_{\text {vap }}=75 \mathrm{~kJ} / \mathrm{mol}$ distributions for dilution factors $<20$. This is not surprising since the $C^{*}$ minimum for the $50 \mathrm{~kJ} / \mathrm{mol}$ assumption considered was also $10^{-2}$. The $E_{\text {loss }}$ for the Dzepina et al. (2009) distributions relative to the $\Delta H_{\text {vap }}=100 \mathrm{~kJ} / \mathrm{mol}$ assumption is larger by 
Table 2. The organic aerosol mass and relative semivolatile gasphase concentrations for the time periods considered from Dzepina et al. (2009).

\begin{tabular}{lllll}
\hline Time of Day & $02: 00$ p.m. & $12: 00$ p.m. & $09: 00$ a.m. & $06: 00$ a.m. \\
\hline$C_{\mathrm{OA}}\left(\mu \mathrm{g} / \mathrm{m}^{3}\right)^{\mathrm{a}}$ & 38 & 23 & 13 & 6 \\
$C_{\mathrm{SVOC}}^{g} / C_{\mathrm{OA}}{ }^{\mathrm{b}}$ & 0.85 & 1.1 & 1.5 & 1.6 \\
\hline
\end{tabular}

${ }^{a}$ For zero dilution.

b Calculated only for $C^{*} \leq 1000 \mu \mathrm{g} / \mathrm{m}^{3}$ compounds.

$\sim 30 \%$ (low DF) to $100 \%$ (high DF) (Fig. 3b). Note that the sensitivity to dilution is essentially independent of time of day and is relatively high as the SOA models used in that study did not form very low volatility material. However, the sensitivity is much lower than that for the two-component model aerosol distribution considered above.

Overall, it has been shown that:

- A significant proportion of the ambient OA can be considered both locally (26\%-71\%) and globally (0\%-59\%) non-volatile. The higher non-volatile fractions correspond to the higher and variable $\Delta H_{\text {vap }}$ assumptions, which are thought to be the most realistic.

- The sensitivity of OA to isothermal dilution is greatest for the volatility distributions derived under the low $\Delta H_{\text {vap }}$ assumptions and lowest for the distributions derived using the high and variable $\Delta H_{\mathrm{vap}}$ assumptions.

- In general, the sensitivity of ambient OA to isothermal dilution as determined using the derived volatility distributions is found to be less than is predicted using a volatility distribution that was determined using a photochemical box-model (Dzepina et al., 2009).

\subsection{Aerosol formation potential}

The amount of available semivolatile gas-phase material $\left(C_{\mathrm{SVOC}}^{g}=\Sigma C_{i \text {,gas }}\right.$, where SVOC indicates semivolatile organic compounds) also depends on the assumed $\Delta H_{\text {vap. This }}$ is important because it represents the amount of "potential" aerosol that might result from further gas-phase chemical processing, or that may condense if the air is cooled by e.g. convective lifting. Our analysis can only place constraints on the $C_{\text {SVOC }}^{g}$ with $C^{*} \leq 1000 \mu \mathrm{g} / \mathrm{m}^{3}$ or $100 \mu \mathrm{g} / \mathrm{m}^{3}$. The constraints are stronger when only bins with $C^{*} \leq 100 \mu \mathrm{g} / \mathrm{m}^{3}$ are considered; for $C^{*}=1000 \mu \mathrm{g} / \mathrm{m}^{3}$, the $C_{\text {SVOC }}^{g}$ estimates should be considered as approximate upper-limits. The abundance of higher volatility material, which does not partition to any significant extent to the particle phase but can still react to produce lower-volatility products, is unconstrained by the TD experiments. The amount of very high-volatility material is generally much larger than the OA concentration, especially for volatile organic compounds (VOC) with
$C^{*}>10^{6} \mu \mathrm{g} / \mathrm{m}^{3}$ (for example, toluene has a $C^{*} \sim 10^{8} \mu \mathrm{g} / \mathrm{m}^{3}$ ). Nonetheless, the estimates of $C_{\text {SVOC }}^{g}$ provided here are useful because a single gas-phase oxidation reaction for these compounds can convert them to compounds with low enough volatility to readily partition to the particle phase. Higher volatility components may need to undergo multiple oxidation steps.

For the fixed $\Delta H_{\text {vap }}$ assumptions, $C_{\mathrm{SVOC}}^{g}$ is found to decrease with increasing $\Delta H_{\mathrm{vap}}$, from $64 \mu \mathrm{g} / \mathrm{m}^{3}\left(\sim 4 \times C_{\mathrm{OA}}\right)$ at $50 \mathrm{~kJ} / \mathrm{mol}$ to $9 \mu \mathrm{g} / \mathrm{m}^{3}\left(\sim 0.5 \times C_{\mathrm{OA}}\right)$ at $150 \mathrm{~kJ} / \mathrm{mol}$ when all bins up to $C^{*}=1000 \mu \mathrm{g} / \mathrm{m}^{3}$ are considered. When only compounds with $C^{*} \leq 100 \mu \mathrm{g} / \mathrm{m}^{3}$ are considered, $C_{\mathrm{SVOC}}^{g}$ ranges from $18 \mu \mathrm{g} / \mathrm{m}^{3}\left(\sim 1 \times C_{\mathrm{OA}}\right)$ for $50 \mathrm{~kJ} / \mathrm{mol}$ to only $4 \mu \mathrm{g} / \mathrm{m}^{3}\left(0.25 \times C_{\mathrm{OA}}\right)$ for $150 \mathrm{~kJ} / \mathrm{mol}$ (Table 1$)$. For the variable $\Delta H_{\text {vap }}$ assumption, $C_{\text {SVOC }}^{g}=26 \mu \mathrm{g} / \mathrm{m}^{3}\left(1.5 \times C_{\mathrm{OA}}\right)$ or $7 \mu \mathrm{g} / \mathrm{m}^{3}\left(\sim 0.4 \times C_{\mathrm{OA}}\right)$ when the $C^{*}=1000 \mu \mathrm{g} / \mathrm{m}^{3}$ bin is included or excluded, respectively. Thus, depending on the assumption as to the appropriate $\Delta H_{\text {vap }}$ distribution to use, the amount of low/semi-volatile gas-phase material (i.e. potential aerosol mass) can vary by up to a factor of 7 . These values can be compared to the Dzepina et al. (2009) results, where the $C_{\mathrm{SVOC}}^{g} / C_{\mathrm{OA}}$ (using $C_{\mathrm{OA}}=17 \mu \mathrm{g} / \mathrm{m}^{3}$ ) varied from 1.2 or 0.7 (at $02: 00$ p.m.) to 1.2 or 0.5 (at $06: 00$ a.m.) when only the $C^{*} \leq 1000 \mu \mathrm{g} / \mathrm{m}^{3}$ or $C^{*} \leq 100 \mu \mathrm{g} / \mathrm{m}^{3}$ compounds are considered, respectively. Thus, the potential aerosol mass derived based on the observed (campaign average) aerosol volatility is, in general, of the same order of magnitude as that from the photochemical box model, depending on the time of day considered. (Note that the discussion of potential aerosol mass given here should not be confused with the concept recently introduced by Kang et al. (2007), which refers to the total amount of aerosol that can be produced from the oxidation of all precursor gases, and not only semivolatile ones.) These values can additionally be compared to estimates of the total observed organic carbon at the T0 site during MILAGRO, where it was found that the ratio between the gas-phase (including the very high-volatility material not constrained by the TD measurements) and the observed OA concentrations was $\sim 37$ (Heald et al., 2008). Thus, the $C_{\text {SVOC }}^{g}$ is found to be only a small fraction of the total gasphase organic material.

Cooling by a few tens of degrees upon convective lifting of the air parcel may also lead to increased partitioning to the particle phase without further chemistry. The magnitude of this gas-to-particle partitioning depends both on the sensitivity to temperature changes of the species vapor pressures (i.e. $\left.\Delta H_{\text {vap }}\right)$ and the available $C_{\mathrm{SVOC}}^{g}$. As an example, we have calculated the increase in $C_{\mathrm{OA}}$ accompanying a decrease in temperature from $25^{\circ} \mathrm{C}$ to $-35^{\circ} \mathrm{C}$ for the various $\Delta H_{\text {vap }}$ assumptions (where the initial $C_{\mathrm{OA}}$ was $17 \mu \mathrm{g} / \mathrm{m}^{3}$ ). It is found that, for temperatures greater than $\sim 10^{\circ} \mathrm{C}$ the increase in $C_{\mathrm{OA}}$ is relatively insensitive to the particular $\Delta H_{\mathrm{vap}}$ assumption used, with SOA mass increases ranging from a factor of 1.2 to 1.5 (only $C^{*} \leq 100 \mu \mathrm{g} / \mathrm{m}^{3}$ ) and 1.4 to 1.9 (including 


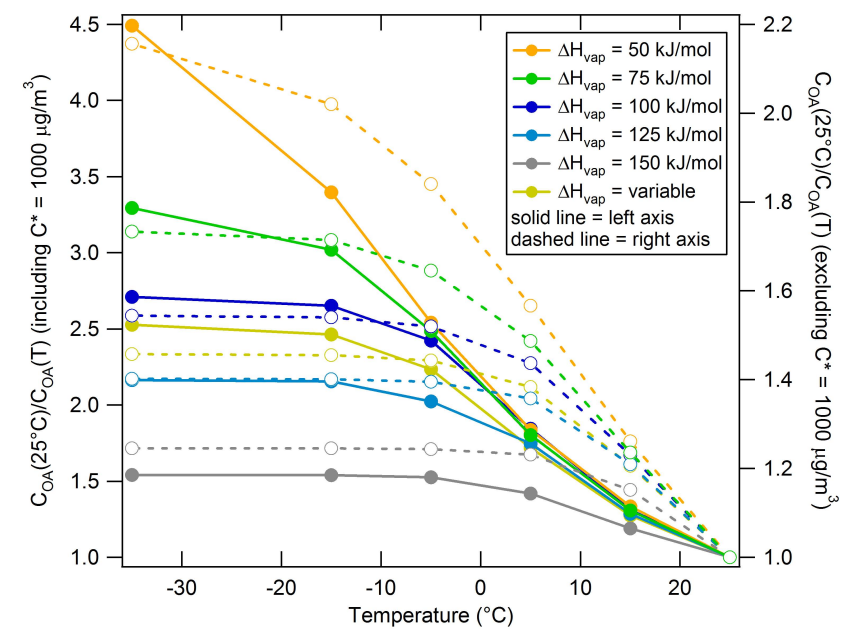

Fig. 4. The calculated increase in $C_{\mathrm{OA}}$ upon cooling from $25^{\circ} \mathrm{C}$ (without dilution) is shown for each of the assumed $\Delta H_{\mathrm{vap}}$. Relative values, i.e. $C_{\mathrm{OA}}\left(25^{\circ} \mathrm{C}\right) / C_{\mathrm{OA}}(T)$, are shown when the $C^{*}=1000 \mu \mathrm{g} / \mathrm{m}^{3}$ bin is included (left axis) and excluded (right axis).

$\left.C^{*}=1000 \mu \mathrm{g} / \mathrm{m}^{3}\right)$ depending on the particular assumptions (Fig. 4). This indicates that over this temperature range the larger $C_{\text {SVOC }}^{g}$ values (i.e. the potentially condensable aerosol mass) associated with the lower $\Delta H_{\text {vap }}$ assumptions are balanced to some extent by the greater sensitivity to temperature changes of the $C^{*}$ values for the higher $\Delta H_{\text {vap }}$ assumption. This is perhaps not surprising since each of the volatility distributions was derived to provide an equivalent response to temperature changes in the thermodenuder regardless of the assumed $\Delta H_{\mathrm{vap}}$, and the range of cooling considered here is very close to the initial range of heating in the TD. At lower temperatures, however, the calculated $C_{\mathrm{OA}}$ for the different $\Delta H_{\text {vap }}$ assumptions diverge, with the lower $\Delta H_{\text {vap }}$ assumptions generally leading to greater calculated $C_{\mathrm{OA}}$. This results from there being overall more potentially condensable mass $\left(C_{\text {SVOC }}^{g}\right)$ for the lower $\Delta H_{\text {vap }}$ assumptions. In the limit of very low temperatures, all of the $C_{\mathrm{SVOC}}^{g}$ will condense to the particle phase, and for many of the $\Delta H_{\text {vap }}$ assumptions considered there is little change in $C_{\mathrm{OA}}$ for temperatures below $0{ }^{\circ} \mathrm{C}$ (Fig. 4). Of additional consideration, it is important to note that the derived volatility distributions must be used in a self-consistent manner, i.e. with the $\Delta H_{\text {vap }}$ assumption from which it was initially derived. For example, if the volatility distribution derived for the $\Delta H_{\text {vap }}=100 \mathrm{~kJ} / \mathrm{mol}$ assumption is assumed to actually have a $\Delta H_{\mathrm{vap}}=50 \mathrm{~kJ} / \mathrm{mol}$, then the $C_{\mathrm{OA}}\left(5^{\circ} \mathrm{C}\right) / C_{\mathrm{OA}}\left(25^{\circ} \mathrm{C}\right)$ is only 1.4 instead of 1.9 .

\subsection{Volatility of different organic aerosol components}

Mass thermograms were determined by Huffman et al. (Huffman et al., 2009a) for the MILAGRO campaign average HOA, BBOA and OOA factors, and the OOA factors were
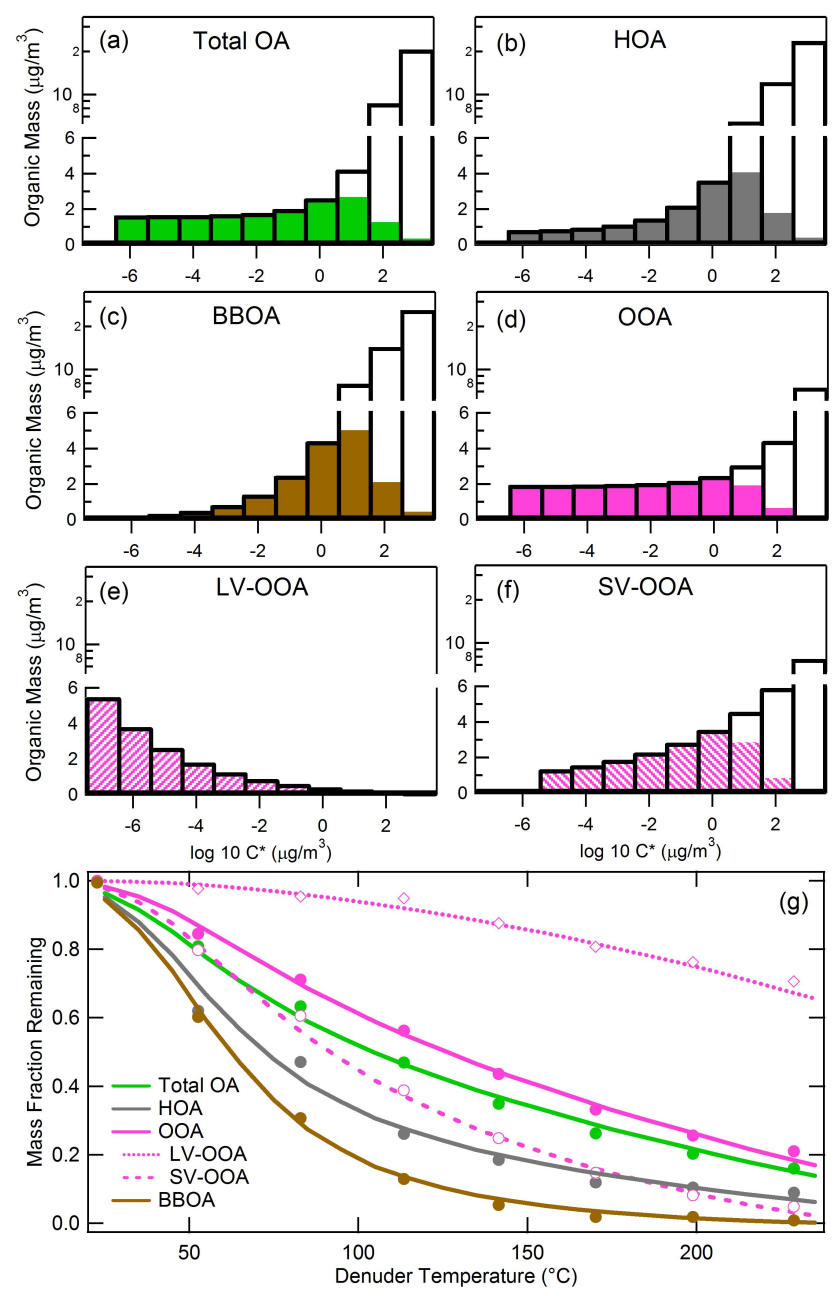

Fig. 5. Volatility distributions derived for the MILAGRO campaign average OA, HOA, BBOA and OOA (including LV-OOA and SV-OOA) factors are shown along with the calculated (assuming $\Delta H_{\text {vap }}=100 \mathrm{~kJ} / \mathrm{mol}$ ) and observed mass thermograms.

further subdivided into OOA-1, more aged, and OOA-2, less aged, factors. Recently the terminology of low-volatility OOA (LV-OOA) and semivolatile OOA (SV-OOA) has been introduced to replace OOA-1 and OOA-2, respectively (Jimenez et al., 2009), and we will adopt this new terminology here. Volatility distributions for each of these aerosol types have been determined from the mass thermograms for each factor reported by Huffman et al. (2009a) (Fig. 5). For consistency with the campaign-average OA analysis above, we use $C_{\mathrm{OA}}=17 \mu \mathrm{g} / \mathrm{m}^{3}$ for each of the OA factors. We also restrict our analysis to the $\Delta H_{\text {vap }}=100 \mathrm{~kJ} / \mathrm{mol}$ assumption since our goal here is only to provide an estimate of how the volatility of the various OA types differ and since its results are similar to those of the variable $\Delta H_{\text {vap }}$ approach (Fig. 2), but without the need for extremely low volatility bins which are uncertain. 
As with the campaign average OA, the assumption that $C_{\text {tot }}$ increases exponentially with $C^{*}$ allows for good model/measurement agreement for each of the OA types determined from factor analysis, with the exception of LVOOA. Instead, to match the model to the observed LV-OOA mass thermogram requires that $C_{\mathrm{tot}}$ is constant or even increases with decreasing $C^{*}$, with both linear and exponential relationships providing reasonable agreement (see Figure S4). We have found that the assumed functional form for LV-OOA has only a very small influence on the calculated non-volatile fraction, sensitivity to dilution and $C_{\mathrm{SVOC}}^{g}$ and thus, for consistency with the campaign average OA and the other OA types, we adopt the exponential relationship for LV-OOA (where the constant in the exponential term is now negative instead of positive, Table 1).

The campaign average OA volatility is determined by the relative abundances of the different OA types weighted by their respective volatilities. The amount of material which is effectively non-volatile under ambient conditions is very different for the different OA types, with the locally non-volatile fraction being $96 \%$ for LV-OOA, $58 \%$ for SV-OOA, $43 \%$ for HOA and $32 \%$ for BBOA. The globally non-volatile fractions go from $88 \%$ for LV-OOA to $28 \%$ for SV-OOA, and are only $22 \%$ for HOA and $9 \%$ for BBOA. (Note that the use of other functional forms for the LV-OOA volatility distribution leads to a range in $f_{n v, g}$ from $84 \%$ to $86 \%$; see Supplementary Material) This confirms that ambient OOA, and especially aged LV-OOA, is of much lower volatility than considered in current SOA models and is effectively non-volatile. This very low-volatility material is most likely the result of photochemical processing, with only a minor fraction being derived from direct emissions. This has important implications for atmospheric modeling, such as global models that can predict a substantial increase in the fraction of OA attributable to SOA in the free troposphere due to the effect of cold ambient temperatures on the semivolatile SOA generated by traditional SOA models (Kanakidou et al., 2005). Additionally, the HOA is somewhat less volatile than source testing suggests for fresh emissions (Robinson et al., 2007; Grieshop et al., 2009b), which may indicate an influence of rapid photochemical processing. BBOA volatility is known to vary with source (Huffman et al., 2009b), and thus the values determined here may be specific to regions dominated by pine burning.

Conversely, the amount of high $C^{*}$ components required to bring the model and observed mass thermograms into agreement is greatest for the BBOA factor, followed by the HOA factor and lowest for the LV-OOA factor. Correspondingly, the gas-phase material available for condensation or further OA formation upon oxidation will be larger for HOA and BBOA periods than for OOA (Table 1). Specifically, $C_{\mathrm{SVOC}}^{g} / C_{\mathrm{OA}}$ is 2.4 for the BBOA factor, 2.1 for the HOA factor, and only 0.7 for the OOA factor (compared with 1.7 for the campaign average OA). Again, it should be kept in mind that this only includes compounds with $C^{*} \leq 10^{3} \mu \mathrm{g} / \mathrm{m}^{3}$, but it does suggest that the potential for further OA formation (specifically photochemically-driven SOA production) is greater when BBOA or HOA are dominant than when OOA is dominant. This result can be rationalized by recognizing that air masses in which OOA is dominant will have already undergone significant photochemical processing, which has led to growth of the particle phase OA at the expense of the semivolatile gas-phase species. However, reactions of high-volatility compounds could lead to the replenishment of the semivolatile pool, thus complicating this simple picture to some extent.

As above, that the different $\mathrm{OA}$ factors have very different volatility distributions means that they also have very different sensitivities to dilution. For example, for a factor of 5 dilution $E_{\text {loss }}$ is $\sim 50 \%$ for BBOA but only $\sim 1 \%$ for LV-OOA (Fig. 6). DeCarlo et al. (2008) observed continuous chemical aging (oxygen gain) of the OA observed around Mexico City over a timescale of a day, even though the OA mass had ceased to increase, and concluded that the aging was much faster than could be explained by heterogeneous oxidation. Our results may help explain this trend, pointing to the evaporation of the more volatile species upon dilution, followed by additional gas-phase oxidation and re-condensation (Grieshop et al., 2009a).

In summary:

- The volatility of the identified OA components follow the order: $\mathrm{BBOA}>\mathrm{HOA}>\mathrm{OA}>\mathrm{HV}-\mathrm{OOA}>\mathrm{LV}-$ OOA.

- LV-OOA was found to be nearly completely nonvolatile and the volatility distribution derived for LVOOA is unique in that lower volatility components are found to be in higher abundance than the higher volatility components.

\subsection{Influence of the evaporation coefficient}

In the above analysis we have assumed that the evaporation coefficient for organic aerosol is unity. However, as discussed above, lower values may be possible (Grieshop et al., 2007, 2009b; Saleh et al., 2009). We consider here how assumptions of $\gamma_{e}=0.1$ or $\gamma_{e}=0.01$ influence our results. To first order, a change in $\gamma_{e}$ can be thought of as equivalent to a change in $C^{*}$, i.e. that from the point of view of evaporation kinetics in the TD, changing $\gamma_{e}$ from 1 to 0.1 has a similar effect as decreasing all the effective $C^{*}$ values by a factor of 10 . Thus, a compound with $C^{*}=100 \mu \mathrm{g} / \mathrm{m}^{3}$ and $\gamma_{e}=0.1$ would evaporate similarly to one with $C^{*}=10 \mu \mathrm{g} / \mathrm{m}^{3}$ and $\gamma_{e}=1$. Conversely, the volatility distributions would shift one bin to the right (towards higher volatilities) if $\gamma_{e}=0.1$ was assumed instead of $\gamma_{e}=1$. Although consideration of $\gamma_{e}$ in this manner is only approximately correct it provides a reasonable basis for interpretation of the results. (Note that we are working under the assumption that $\gamma_{e}$ does not influence the initial equilibrium state since much longer equilibration 


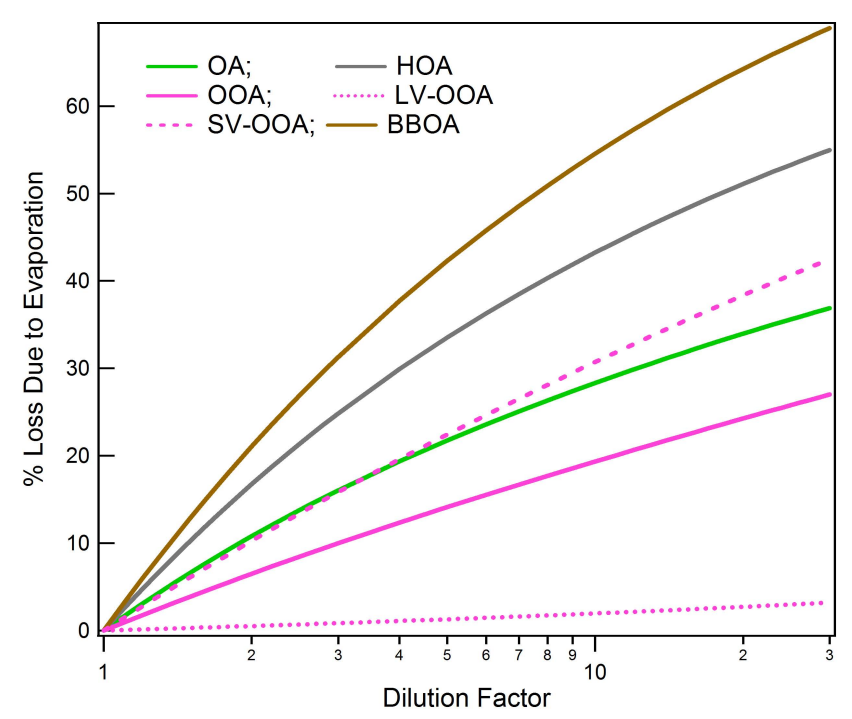

Fig. 6. The $E_{\text {loss }}$ (i.e. the additional mass loss due to evaporation after dilution) is shown as a function of the dilution factor for the various campaign average $\mathrm{OA}$ factors (assuming $\Delta H_{\mathrm{vap}}=100 \mathrm{~kJ} / \mathrm{mol}$ ).

times are available in the atmosphere and therefore the initial distribution between the gas and particle phases will still behave as if $C^{*}=100 \mu \mathrm{g} / \mathrm{m}^{3}$.)

Starting with $\gamma_{e}=0.01$, we find that it is not possible to find a volatility distribution for any assumed $\Delta H_{\text {vap }}$ that yields good model-measurement agreement over the entire temperature range (see Fig. S5). In particular, it is at low-temperatures where the discrepancy is most apparent. This is because when $\gamma_{e}=0.01$ the particles do not evaporate fast enough in the model at low temperatures and thus the calculated mass fraction remaining is too large for thermodenuder temperatures less than $\sim 75^{\circ} \mathrm{C}$. This is perhaps not surprising since evaporation at the lowest thermodenuder temperatures is governed by the highest volatility components and when $\gamma_{e}=0.01$ the $C^{*}=1000 \mu \mathrm{g} / \mathrm{m}^{3}$ and $C^{*}=100 \mu \mathrm{g} / \mathrm{m}^{3}$ compounds are effectively behaving as if they were $C^{*}=10 \mu \mathrm{g} / \mathrm{m}^{3}$ and $C^{*}=1 \mu \mathrm{g} / \mathrm{m}^{3}$ compounds. The largest disagreement is found for the low constant $\Delta H_{\text {vap }}$ assumptions; for larger assumed $\Delta H_{\text {vap }}$ the modelmeasurement disagreement decreases overall, but inconsistencies remain for the lowest temperatures (see Figure S5). As such, the observations appear to rule out $\gamma_{e}$ values as low as 0.01 for ambient organic aerosol and certainly rule out lower values (i.e. 0.001).

Considering now $\gamma_{e}=0.1$, we find that it is possible to find $C_{\text {tot }}$ distributions that are generally consistent with the observations. However, as might be expected, more mass must be placed in higher volatility bins, compared to the $\gamma_{e}=1$ case, in order to have sufficient particle evaporation at low temperatures in the TD. As a result the aerosol formation potential (i.e. $C_{\mathrm{SVOC}}^{g}$ ) is increased, by approximately $30-80 \%$ compared to the $\gamma_{e}=1$ case (Table 1 ). The total OA mass be- comes somewhat more sensitive to dilution when the $\gamma_{e}=0.1$ distributions are used, with the $E_{\text {loss }}$ terms for $\gamma_{e}=0.1$ being greater than the $E_{\text {loss }}$ terms for $\gamma_{e}=1$ for all cases considered (Fig. S6). The increase in $C_{\mathrm{OA}}$ upon cooling is also greater for the $\gamma_{e}=0.1$ cases, with $C_{\mathrm{OA}}\left(5^{\circ} \mathrm{C}\right)$ being approximately $25 \%$ higher when $\gamma_{e}=0.1$ than when $\gamma_{e}=1$, starting from the same $C_{\mathrm{OA}}\left(25^{\circ} \mathrm{C}\right)$. Since this is an equilibrium calculation this result derives directly from the greater $C_{\mathrm{SVOC}}^{g}$ values for the $\gamma_{e}=0.1$ case.

In summary:

- Comparison between modeled and measured OA mass thermograms suggests that the evaporation coefficient for ambient $\mathrm{OA}$ is $>10^{-2}$.

- If $\gamma_{e}<1$, the derived volatility distributions suggest an OA that is overall more volatile with an increased amount of semi-volatile gas-phase species available.

\section{Conclusions}

Measurements of the change in the total organic aerosol mass in response to changes in temperature provide a measure of the volatility of the components comprising the aerosol particles. Here, we have compared OA volatility measurements from Mexico City with results from a physicallybased model to determine volatility distributions that are quantitatively consistent with the observations. An exponential relationship between $C_{i \text {,tot }}$ (the total organic concentration in each bin of the basis set) and $C_{i}^{*}$ provides for good model/measurement agreement. A constraint on our conclusions arises from the vaporization enthalpies of the OA components not being known a priori, and thus we have presented volatility distributions for different reasonable assumptions about $\Delta H_{\text {vap. }}$.

Use of a semi-empirical relationship between $C^{*}$ and $\Delta H_{\text {vap }}$ (Epstein et al., 2009) does not allow for model/measurement agreement over the entire temperature range for any assumed volatility distribution. However, when a modified version of this relationship is used, where an upper limit on the $\Delta H_{\text {vap }}$ values of $200 \mathrm{~kJ} / \mathrm{mol}$ is applied, model/measurement agreement can be obtained. From this relationship, the majority of the $\mathrm{OA}$ is found to be nonvolatile (ca. 50-90\%, depending on the definition of nonvolatile used) and extremely low volatility material (with $C^{*}<10^{-10} \mu \mathrm{g} / \mathrm{m}^{3}$ ) is required. As an alternative, we have also considered a series of cases where $\Delta H_{\text {vap }}$ is assumed to be constant and independent of $C^{*}$. For these situations we find that in general: (1) the abundance of non-volatile material increases with the assumed $\Delta H_{\mathrm{vap}}$; (2) the sensitivity of the OA abundance to dilution increases with decreasing $\Delta H_{\mathrm{vap}}$; and (3) the aerosol formation potential, i.e. the amount of semi-volatile gas-phase material, is greater for lower assumed $\Delta H_{\text {vap }}$. It is possible to fit the ambient observations assuming a 1 or 2 -product model with parameters 
similar to those derived from traditional chamber-based 2product models. However with a 1 or 2 -product model there is no material at all which is atmospherically non-volatile, and the OA is found to be extremely sensitive to dilution, likely to a physically unrealistic extent.

We have additionally used the empirical relationship between $T_{50}$ and $C^{*}$ established by Faulhaber et al. (2009) to independently determine a volatility distribution for the MILAGRO OA. This method yields a volatility distribution similar to the $\Delta H_{\text {vap }}=150 \mathrm{~kJ} / \mathrm{mol}$ and the variable $\Delta H_{\text {vap }}$ assumptions, and the resulting global non-volatile fraction is $56 \%$.

Volatility distributions were also determined for the various OA factors determined from PMF analysis of the OA mass spectral time-series. It was found that BBOA (biomass burning OA) was the most volatile, followed by HOA (hydrocarbon-like OA), SV-OOA (semivolatile oxygenated $\mathrm{OA}$ ) and then LV-OOA (low volatility oxygenated OA). Correspondingly, the aerosol formation potential is greatest for BBOA and lowest for LV-OOA. LV-OOA, which is a substantial fraction of the global OA burden (Jimenez et al., 2009), is found to be almost entirely non-volatile while $<25 \%$ of HOA and BBOA can be considered globally nonvolatile.

The influence of the evaporation coefficient on the derived volatility distributions was also considered. When the assumed $\gamma_{e}$ was decreased from 1 to 0.1 , the derived semi-volatile gas-phase material in equilibrium with the OA (which is a potential source of additional aerosol mass) increased as did the sensitivity of the equilibrium aerosol mass to dilution and changes in temperature. It was determined that the observations are generally inconsistent with an assumed evaporation coefficient of $10^{-2}$ or lower.

Although these results cannot provide a single, definitive volatility distribution for organic aerosol in Mexico City (and other polluted urban regions) due to the uncertainties in $\Delta H_{\text {vap }}$ and $\gamma_{e}$, they nonetheless provide the first quantitative estimates of the volatility of ambient OA and, using a semiempirical estimate of $\Delta H_{\text {vap }}$ for OA, suggest that much of the OA mass is effectively non-volatile. It is important to note that the derived volatility distributions must be used in a self-consistent manner, i.e. that the volatility distribution derived for a particular $\Delta H_{\text {vap }}$ assumption not be used with

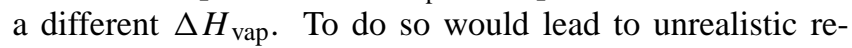
sponses of the OA mass due to temperature changes accompanying e.g. convective lofting or diurnal cycles.

\section{Supplementary material related to this article is available online at: \\ http://www.atmos-chem-phys.net/10/5409/2010/ acp-10-5409-2010-supplement.pdf.}

Acknowledgements. This research was partially funded by grants EPA STAR-R833747 and NOAA NA08OAR4310565.

Edited by: L. Molina

\section{References}

Aiken, A. C., Salcedo, D., Cubison, M. J., Huffman, J. A., DeCarlo, P. F., Ulbrich, I. M., Docherty, K. S., Sueper, D., Kimmel, J. R., Worsnop, D. R., Trimborn, A., Northway, M., Stone, E. A., Schauer, J. J., Volkamer, R. M., Fortner, E., de Foy, B., Wang, J., Laskin, A., Shutthanandan, V., Zheng, J., Zhang, R., Gaffney, J., Marley, N. A., Paredes-Miranda, G., Arnott, W. P., Molina, L. T., Sosa, G., and Jimenez, J. L.: Mexico City aerosol analysis during MILAGRO using high resolution aerosol mass spectrometry at the urban supersite (T0) - Part 1: Fine particle composition and organic source apportionment, Atmos. Chem. Phys., 9, 66336653, 2009,

http://www.atmos-chem-phys.net/9/6633/2009/.

Aiken, A. C., de Foy, B., Wiedinmyer, C., DeCarlo, P. F., Ulbrich, I. M., Wehrli, M. N., Szidat, S., Prevot, A. S. H., Noda, J., Wacker, L., Volkamer, R., Fortner, E., Wang, J., Laskin, A., Shutthanandan, V., Zheng, J., Zhang, R., Paredes-Miranda, G., Arnott, W. P., Molina, L. T., Sosa, G., Querol, X., and Jimenez, J. L.: Mexico City aerosol analysis during MILAGRO using high resolution aerosol mass spectrometry at the urban supersite (T0) - Part 2: Analysis of the biomass burning contribution and the non-fossil carbon fraction, Atmos. Chem. Phys., 10, 5315-5341, doi:10.5194/acp-10-5315-2010, 2010.

Cammenga, H. K.: Evaporation Mechanisms of Liquids, in: Current Topics in Materials Science 5, edited by: Kaldis, E., NorthHolland, Amsterdam, The Netherlands, 335-446, 1980.

Cappa, C. D., Lovejoy, E. R., and Ravishankara, A. R.: Determination of Evaporation Rates and Vapor Pressures of Very Low Volatility Compounds: A Study of the C4-C10 and C12 Dicarboxylic Acids, J. Phys. Chem. A, 111, 3099-3109, 2007.

Cappa, C. D., Lovejoy, E. R., and Ravishankara, A. R.: Evidence for liquid-like and non-ideal behavior of a mixture of organic aerosol components, Proc. Natl. Acad. Sci., 105, 18687-18691, doi:10.1073/pnas.0802144105, 2008.

Cappa, C. D.: A model of aerosol evaporation kinetics in a thermodenuder, Atmos. Meas. Technol., 3, 579-592, doi:10.5194/amt-3579-2010, 2010.

Chickos, J. S. and Acree, W. E.: Enthalpies of vaporization of organic and organometallic compounds, 1880-2002, J. Phys. Chem. Ref. Data, 32, 519-878, 2003.

Davis, E. J., Ravindran, P., and Ray, A. K.: A review of theory and experiments on diffusion from submicroscopic particles, Chem. Eng. Comm., 5, 251-268, 1980.

de Gouw, J. and Jimenez, J. L.: Organic Aerosols in the Earth's Atmosphere, Environ. Sci. Technol., 43, 7614-7618, doi:10.1021/es9006004, 2009.

de Gouw, J. A., Middlebrook, A. M., Warneke, C., Goldan, P. D., Kuster, W. C., Roberts, J. M., Fehsenfeld, F. C., Worsnop, D. R., Canagaratna, M. R., Pszenny, A. A. P., Keene, W. C., Marchewka, M., Bertman, S. B., and Bates, T. S.: Budget of organic carbon in a polluted atmosphere: Results from the New England Air Quality Study in 2002, J. Geophys. Res.-Atmos., 110, D16305, doi:10.1029/2004JD005623, 2005. 
DeCarlo, P. F., Kimmel, J. R., Trimborn, A., Northway, M. J., Jayne, J. T., Aiken, A. C., Gonin, M., Fuhrer, K., Horvath, T., Docherty, K. S., Worsnop, D. R., and Jimenez, J. L.: Field-deployable, high-resolution, time-of-flight aerosol mass spectrometer, Anal. Chem., 78, 8281-8289, doi:10.1021/ac061249n, 2006.

DeCarlo, P. F., Dunlea, E. J., Kimmel, J. R., Aiken, A. C., Sueper, D., Crounse, J., Wennberg, P. O., Emmons, L., Shinozuka, Y., Clarke, A., Zhou, J., Tomlinson, J., Collins, D. R., Knapp, D., Weinheimer, A. J., Montzka, D. D., Campos, T., and Jimenez, J. L.: Fast airborne aerosol size and chemistry measurements above Mexico City and Central Mexico during the MILAGRO campaign, Atmos. Chem. Phys., 8, 4027-4048, 2008, http://www.atmos-chem-phys.net/8/4027/2008/.

Denkenberger, K. A., Moffet, R. C., Holecek, J. C., Rebotier, T. P., and Prather, K. A.: Real-Time, Single-Particle Measurements of Oligomers in Aged Ambient Aerosol Particles, Environ. Sci. Technol., 41, 5439-5446, doi:10.1021/es0703291, 2007.

Docherty, K. S., Stone, E. A., Ulbrich, I. M., DeCarlo, P. F., Snyder, D. C., Schauer, J. J., Peltier, R. E., Weber, R. J., Murphy, S. M., Seinfeld, J. H., Grover, B. D., Eatough, D. J., and Jimenez, J. L.: Apportionment of Primary and Secondary Organic Aerosols in Southern California during the 2005 Study of Organic Aerosols in Riverside (SOAR-1), Environ. Sci. Technol., 42, 7655-7662, doi:10.1021/es8008166, 2008.

Donahue, N. M., Hartz, K. E. H., Chuong, B., Presto, A. A., Stanier, C. O., Rosenhorn, T., Robinson, A. L., and Pandis, S. N.: Critical factors determining the variation in SOA yields from terpene ozonolysis: A combined experimental and computational study, Faraday Discuss., 130, 295-309, 2005.

Donahue, N. M., Robinson, A. L., Stanier, C. O., and Pandis, S. N.: Coupled partitioning, dilution, and chemical aging of semivolatile organics, Environ. Sci. Technol., 40, 2635-2643, 2006.

Dzepina, K., Volkamer, R., Madronich, S., Tulet, P., Ulbrich, I., Zhang, Q., Cappa, C. D., Ziemann, P. J., and Jimenez, J. L.: Evaluation of New Secondary Organic Aerosol (SOA) Models for a Case Study in Mexico City, Atmos. Chem. Phys., 9, 56815709, 2009, http://www.atmos-chem-phys.net/9/5681/2009/.

Epstein, S. A., Riipinen, I., and Donahue, N. M.: A Semiempirical Correlation between Enthalpy of Vaporization and Saturation Concentration for Organic Aerosol, Environ. Sci. Technol., 44, 743-748, doi:10.1021/es902497z, 2009.

Faulhaber, A. E., Thomas, B. M., Jimenez, J. L., Jayne, J. T., Worsnop, D., and Ziemann, P. J.: Characterization of a thermodenuderparticle beam mass spectrometer system for the study of organic aerosol volatility and composition, Atmos. Meas. Tech., 2, 15-31, 2009, http://www.atmos-meas-tech.net/2/15/2009/.

Goldstein, A. H. and Galbally, I. E.: Known and unexplored organic constituents in the earth's atmosphere, Environ. Sci. Technol., 41, 1514-1521, 2007.

Grieshop, A. P., Donahue, N. M., and Robinson, A. L.: Is the gas-particle partitioning in alpha-pinene secondary organic aerosol reversible?, Geophys. Res. Lett., 34, L14810, doi:10.1029/2007GL029987, 2007.

Grieshop, A. P., Logue, J. M., Donahue, N. M., and Robinson, A. L.: Laboratory investigation of photochemical oxidation of organic aerosol from wood fires 1: measurement and simulation of organic aerosol evolution, Atmos. Chem. Phys., 9, 1263-1277, 2009a, http://www.atmos-chem-phys.net/9/1263/2009/.
Grieshop, A. P., Miracolo, M. A., Donahue, N. M., and Robinson, A. L.: Constraining the Volatility Distribution and Gas-Particle Partitioning of Combustion Aerosols Using Isothermal Dilution and Thermodenuder Measurements, Environ. Sci. Technol., 43, 4750-4756, doi:10.1021/es8032378, 2009b.

Griffin, R. J., Cocker, D. R., Flagan, R. C., and Seinfeld, J. H.: Organic aerosol formation from the oxidation of biogenic hydrocarbons, J. Geophys. Res.-Atmos, 104, 3555-3567, 1999.

Hallquist, M., Wenger, J. C., Baltensperger, U., Rudich, Y., Simpson, D., Claeys, M., Dommen, J., Donahue, N. M., George, C., Goldstein, A. H., Hamilton, J. F., Herrmann, H., Hoffmann, T., Iinuma, Y., Jang, M., Jenkin, M. E., Jimenez, J. L., KiendlerScharr, A., Maenhaut, W., McFiggans, G., Mentel, T. F., Monod, A., Prévôt, A. S. H., Seinfeld, J. H., Surratt, J. D., Szmigielski, R., and Wildt, J.: The formation, properties and impact of secondary organic aerosol: current and emerging issues, Atmos. Chem. Phys., 9, 5155-5236, 2009,

http://www.atmos-chem-phys.net/9/5155/2009/.

Heald, C. L., Jacob, D. J., Park, R. J., Russell, L. M., Huebert, B. J., Seinfeld, J. H., Liao, H., and Weber, R. J.: A large organic aerosol source in the free troposphere missing from current models, Geophys. Res. Lett., 32, L18809, doi:18810.11029/12005GL023831, 2005.

Heald, C. L., Goldstein, A. H., Allan, J. D., Aiken, A. C., Apel, E., Atlas, E. L., Baker, A. K., Bates, T. S., Beyersdorf, A. J., Blake, D. R., Campos, T., Coe, H., Crounse, J. D., DeCarlo, P. F., de Gouw, J. A., Dunlea, E. J., Flocke, F. M., Fried, A., Goldan, P., Griffin, R. J., Herndon, S. C., Holloway, J. S., Holzinger, R., Jimenez, J. L., Junkermann, W., Kuster, W. C., Lewis, A. C., Meinardi, S., Millet, D. B., Onasch, T., Polidori, A., Quinn, P. K., Riemer, D. D., Roberts, J. M., Salcedo, D., Sive, B., Swanson, A. L., Talbot, R., Warneke, C., Weber, R. J., Weibring, P., Wennberg, P. O., Worsnop, D. R., Wittig, A. E., Zhang, R., Zheng, J., and Zheng, W.: Total observed organic carbon (TOOC) in the atmosphere: a synthesis of North American observations, Atmos. Chem. Phys., 8, 2007-2025, 2008, http://www.atmos-chem-phys.net/8/2007/2008/.

Hilal, S. H., Karickhoff, S. W., and Carreira, L. A.: Prediction of the vapor pressure boiling point, heat of vaporization and diffusion coefficient of organic compounds, QSAR Comb. Sci., 22, 565574, 2003.

Huffman, J. A., Ziemann, P. J., Jayne, J. T., Worsnop, D. R., and Jimenez, J. L.: Development and characterization of a fast-stepping/scanning thermodenuder for chemically-resolved aerosol volatility measurements, Aerosol Sci. Technol., 42, 395407, 10.1080/02786820802104981, 2008.

Huffman, J. A., Docherty, K. S., Aiken, A. C., Cubison, M. J., Ulbrich, I. M., DeCarlo, P. F., Sueper, D., Jayne, J. T., Worsnop, D., Ziemann, P. J., and Jimenez, J. L.: Chemically-Resolved volatility measurements from two megacity field studies, Atmos. Chem. Phys., 9, 7161-7182, 2009a, http://www.atmos-chem-phys.net/9/7161/2009/.

Huffman, J. A., Docherty, K. S., Mohr, C., Cubison, M. J., Ulbrich, I. M., Ziemann, P. J., Onasch, T. B., and Jimenez, J. L.: Chemically-Resolved volatility measurements of organic aerosol from different sources, Environ. Sci. Technol., 43, 5351-5357, doi:10.1021/es803539d, 2009b.

IPCC: Climate Change: The Physical Science Basis - Contribution of Working Group I to the Fourth Assessment Report of the Inter- 
governmental Panel on Climate Change, edited by: Solomon, S., Qin, D., and Manning, M., Cambridge University Press, Cambridge, 996 pp., 2007.

Jimenez, J. L., Canagaratna, M. R., Donahue, N. M., Prevot, A. S. H., Zhang, Q., Kroll, J. H., DeCarlo, P. F., Allan, J. D., Coe, H., Ng, N. L., Aiken, A. C., Docherty, K. S., Ulbrich, I. M., Grieshop, A. P., Robinson, A. L., Duplissy, J., Smith, J. D., Wilson, K. R., Lanz, V. A., Hueglin, C., Sun, Y. L., Tian, J., Laaksonen, A., Raatikainen, T., Rautiainen, J., Vaattovaara, P., Ehn, M., Kulmala, M., Tomlinson, J. M., Collins, D. R., Cubison, M. J., Dunlea, E. J., Huffman, J. A., Onasch, T. B., Alfarra, M. R., Williams, P. I., Bower, K., Kondo, Y., Schneider, J., Drewnick, F., Borrmann, S., Weimer, S., Demerjian, K., Salcedo, D., Cottrell, L., Griffin, R., Takami, A., Miyoshi, T., Hatakeyama, S., Shimono, A., Sun, J. Y., Zhang, Y. M., Dzepina, K., Kimmel, J. R., Sueper, D., Jayne, J. T., Herndon, S. C., Trimborn, A. M., Williams, L. R., Wood, E. C., Middlebrook, A. M., Kolb, C. E., Baltensperger, U., and Worsnop, D. R.: Evolution of Organic Aerosols in the Atmosphere, Science, 326, 1525-1529, doi:10.1126/science.1180353, 2009.

Johnson, D., Utembe, S. R., Jenkin, M. E., Derwent, R. G., Hayman, G. D., Alfarra, M. R., Coe, H., and McFiggans, G.: Simulating regional scale secondary organic aerosol formation during the TORCH 2003 campaign in the southern UK, Atmos. Chem. Phys., 6, 403-418, 2006,

http://www.atmos-chem-phys.net/6/403/2006/.

Kalberer, M., Paulsen, D., Sax, M., Steinbacher, M., Dommen, J., Prevot, A. S. H., Fisseha, R., Weingartner, E., Frankevich, V., Zenobi, R., and Baltensperger, U.: Identification of polymers as major components of atmospheric organic aerosols, Science, 303, 1659-1662, 2004.

Kanakidou, M., Seinfeld, J. H., Pandis, S. N., Barnes, I., Dentener, F. J., Facchini, M. C., Van Dingenen, R., Ervens, B., Nenes, A., Nielsen, C. J., Swietlicki, E., Putaud, J. P., Balkanski, Y., Fuzzi, S., Horth, J., Moortgat, G. K., Winterhalter, R., Myhre, C. E. L., Tsigaridis, K., Vignati, E., Stephanou, E. G., and Wilson, J.: Organic aerosol and global climate modelling: a review, Atmos. Chem. Phys., 5, 1053-1123, 2005,

http://www.atmos-chem-phys.net/5/1053/2005/.

Kang, E., Root, M. J., Toohey, D. W., and Brune, W. H.: Introducing the concept of Potential Aerosol Mass (PAM), Atmos. Chem. Phys., 7, 5727-5744, 2007,

http://www.atmos-chem-phys.net/7/5727/2007/.

Kleinman, L. I., Springston, S. R., Daum, P. H., Lee, Y. N., Nunnermacker, L. J., Senum, G. I., Wang, J., Weinstein-Lloyd, J., Alexander, M. L., Hubbe, J., Ortega, J., Canagaratna, M. R., and Jayne, J.: The time evolution of aerosol composition over the Mexico City plateau, Atmos. Chem. Phys., 8, 1559-1575, 2008, http://www.atmos-chem-phys.net/8/1559/2008/.

Kulmala, M. and Wagner, P. E.: Mass accommodation and uptake coefficients - a quantitative comparison, J. Aerosol Sci., 32, 833841, 2001.

MacLeod, M., Scheringer, M., and Hungerbühler, K.: Estimating Enthalpy of Vaporization from Vapor Pressure Using Trouton's Rule, Environ. Sci. Technol., 41, 2827-2832, doi:10.1021/es0608186, 2007.

Marcolli, C., Luo, B. P., Peter, T., and Wienhold, F. G.: Internal mixing of the organic aerosol by gas phase diffusion of semivolatile organic compounds, Atmos. Chem. Phys., 4, 2593-
2599, 2004, http://www.atmos-chem-phys.net/4/2593/2004/.

Molina, L. T., Madronich, S., Gaffney, J. S., Apel, E., de Foy, B., Fast, J., Ferrare, R., Herndon, S., Jimenez, J. L., Lamb, B., Osornio-Vargas, A. R., Russell, P., Schauer, J. J., Stevens, P. S., and Zavala, M.: An overview of the MILAGRO 2006 campaign: Mexico City emissions and their transport and transformation, Atmos. Chem. Phys. Discuss., 10, 7819-7983, doi:10.5194/acpd-10-7819-2010, 2010.

Nel, A.: Air Pollution-Related Illness: Effects of Particles, Science, 308, 804-806, doi:10.1126/science.1108752, 2005.

Odum, J. R., Hoffmann, T., Bowman, F., Collins, D., Flagan, R. C., and Seinfeld, J. H.: Gas/particle partitioning and secondary organic aerosol yields, Environ. Sci. Technol., 30, 2580-2585, 1996.

Offenberg, J. H., Kleindienst, T. E., Jaoui, M., Lewandowski, M., and Edney, E. O.: Thermal properties of secondary organic aerosols, Geophys. Res. Lett., 33, L03816, doi:10.1029/2005GL024623, 2006.

Pankow, J. F.: An Absorption-Model of Gas-Particle Partitioning of Organic-Compounds in the Atmosphere, Atmos. Environ., 28, 185-188, 1994.

Pankow, J. F. and Barsanti, K. C.: The carbon numberpolarity grid: A means to manage the complexity of the mix of organic compounds when modeling atmospheric organic particulate matter, Atmos. Environ., 43, 2829-2835, doi:10.1016/j.atmosenv.2008.12.050, 2009.

Pope, C. A. and Dockery, D. W.: Health effects of fine particulate air pollution: Lines that connect, J. Air Waste Manage. Assoc., 56, 709-742, 2006.

Pound, G. M.: Selected Values of Evaporation and Condensation Coefficients for Simple Substance, J. Phys. Chem. Ref. Data, 1, 135-146, 1972.

Presto, A. A. and Donahue, N. M.: Investigation of alpha-pinene plus ozone secondary organic aerosol formation at low total aerosol mass, Environ. Sci. Technol., 40, 3536-3543, 2006.

Robinson, A. L., Donahue, N. M., Shrivastava, M. K., Weitkamp, E. A., Sage, A. M., Grieshop, A. P., Lane, T. E., Pierce, J. R., and Pandis, S. N.: Rethinking organic aerosols: Semivolatile emissions and photochemical aging, Science, 315, 1259-1262, 2007.

Saleh, R., Shihadeh, A., and Khlystov, A.: Determination of evaporation coefficients of semi-volatile organic aerosols using an integrated volume-tandem differential mobility analysis (IV-TDMA) method J. Aerosol Sci., 40, 1019-1029, doi:10.1016/j.jaerosci.2009.09.008, 2009.

Smith, J. D., Kroll, J. H., Cappa, C. D., Che, D. L., Ahmed, M., Leone, S. R., Worsnop, D., and Wilson, K. R.: The Heterogeneous OH Oxidation of Sub-micron Squalane Particle: A Model System for Probing the Underlying Chemical Mechanisms that Control Ageing of Ambient Aerosols, Atmos. Chem. Phys., 9, 3209-3222, 2009, http://www.atmos-chem-phys.net/9/3209/2009/.

Stanier, C. O., Pathak, R. K., and Pandis, S. N.: Measurements of the Volatility of Aerosols from $\alpha$-Pinene Ozonolysis, Environ. Sci. Technol., 41, 2756-2763, 2007.

Ulbrich, I. M., Canagaratna, M. R., Zhang, Q., Worsnop, D. R., and Jimenez, J. L.: Interpretation of organic components from Positive Matrix Factorization of aerosol mass spectrometric data, Atmos. Chem. Phys., 9, 2891-2918, 2009, http://www.atmos-chem-phys.net/9/2891/2009/. 
Volkamer, R., Jimenez, J. L., San Martini, F., Dzepina, K., Zhang, Q., Salcedo, D., Molina, L. T., Worsnop, D. R., and Molina, M. J.: Secondary organic aerosol formation from anthropogenic air pollution: Rapid and higher than expected, Geophys. Res. Lett., 33, L17811, doi:10.1029/2006GL026899, 2006.

Zhang, Q., Jimenez, J. L., Canagaratna, M. R., Allan, J. D., Coe, H., Ulbrich, I., Alfarra, M. R., Takami, A., Middlebrook, A. M., Sun, Y. L., Dzepina, K., Dunlea, E., Docherty, K., DeCarlo, P. F., Salcedo, D., Onasch, T., Jayne, J. T., Miyoshi, T., Shimono, A., Hatakeyama, S., Takegawa, N., Kondo, Y., Schneider, J., Drewnick, F., Borrmann, S., Weimer, S., Demerjian, K., Williams, P., Bower, K., Bahreini, R., Cottrell, L., Griffin, R. J., Rautiainen, J., Sun, J. Y., Zhang, Y. M., and Worsnop, D. R.: Ubiquity and dominance of oxygenated species in organic aerosols in anthropogenically-influenced Northern Hemisphere midlatitudes, Geophys. Res. Lett., 34, L13801, doi:10.1029/2007GL029979, 2007. 